\title{
On the basicity of conjugated nitrogen heterocycles in different media
}

\author{
Märt Lõkov, ${ }^{1}$ Sofja Tshepelevitsh, ${ }^{1}$ Agnes Heering,,${ }^{1}$ Paul G. Plieger, ${ }^{2}$ Robert Vianello, ${ }^{3}$ Ivo \\ Leito ${ }^{*}, 1$ \\ ${ }^{1}$ University of Tartu, Institute of Chemistry, Ravila 14a, Tartu 50411, Estonia \\ ${ }^{2}$ Institute of Fundamental Sciences, Massey University, Private Bag 11 222, \\ Palmerston North, New Zealand \\ ${ }^{3}$ Computational Organic Chemistry and Biochemistry Group, Ruđer Bošković Institute, \\ Bijenička cesta 54, HR-10000 Zagreb, Croatia.
}

\begin{abstract}
This work explores the relationship between the structure and solvent effects on the basicity of a large selection of conjugated N-heterocyclic nitrogen bases in different media: polar aprotic solvent acetonitrile, polar protic solvent water and the gas phase. Altogether 58 previously unpublished basicity values in different media for 39 compounds are presented, including 30 experimentally determined $\mathrm{p} K_{\mathrm{a}}$ values in acetonitrile. We present the $\mathrm{p} K_{\mathrm{a}}$ and gas phase basicity values for quino[7,8-h]quinoline, which is one of the most basic conjugated nitrogen heterocyclic compounds without basicity-enhancing substituents. The basicity trends are rationalized by comparing basicity data of related compounds in different solvents, as well as by using isodesmic reactions. The gas-phase basicity is predominantly determined by the ability of a molecule to disperse the excess positive charge over a large number of atoms. In solution the situation is less clear and smaller systems with localized charge often lead to higher basicities because of solvent effects. In particular, it was found that fusion of an additional benzene ring does not always lead to basicity increase in solution: its effect can be either basicity-increasing or decreasing, depending on the ring size, number and position of nitrogen atoms and medium. Correlation between measured $\mathrm{p} K_{\mathrm{a}}$ values in $\mathrm{MeCN}$ and in water suggests that these two different solvents exert similar effect on the basicity of the studied heterocycles.
\end{abstract}

\footnotetext{
*Corresponding author, e-mail: ivo.leito@ut.ee, http://analytical.chem.ut.ee/.
} 


\section{Introduction}

Conjugated heterocyclic compounds containing one or more nitrogen atoms in the ring(s) are very common in nature, research and technology. Many such compounds have a strong bioactive effect and a large part of drugs, poisons, dyes, pesticides and narcotics contain heterocycles in their structure. ${ }^{[1]}$ They are also widely used in organic synthesis as reactants, catalysts or solvents.

Almost all N-heterocycles are basic compounds and often the basicity is essential to the properties of these compounds, as it, for example, determines their ability to take part in hydrogen bonding interactions. ${ }^{[2]}$ In the case of drugs, the basicity is important because the absorption of drugs is dependent on the their basicity. ${ }^{[3]}$ Also, in organic synthesis it is beneficial to know the basicity of a compound to determine whether or not the compound is protonated, thus correctly establish its protonation state.

The basicity of heterocyclic compounds in water has been extensively studied and, therefore, aqueous $\mathrm{p} K_{\mathrm{a}}$ values of many different types of heterocycles are available. ${ }^{[4-16]}$ In non-aqueous media the situation is the opposite. Besides the scarcity of basicity data for N-heterocycles in non-aqueous solvents, the $\mathrm{p} K_{\mathrm{a}}$ values obtained by different groups are sometimes inconsistent. ${ }^{[17]}$ Although basicity and acidity values have been reported for different dipolar aprotic solvents, the data are often incomparable because of the different methods and conditions used for basicity determinations. ${ }^{[18]}$ The previously established self-consistent basicity scale in acetonitrile ${ }^{[17]}$ makes it possible to determine accurate $\mathrm{p} K_{\mathrm{a}}$ values for the Nheterocyclic compounds studied in this paper. In addition to acetonitrile, basicity values in tetrahydrofuran ${ }^{[19]}, 1,2$-dichloroethane ${ }^{[20]}$ and the gas phase ${ }^{[21]}$ have been previously published by our group.

It appears that in the gas phase the experimental basicity data of heterocyclic compounds is also limited. Only for $55 \%$ of the compounds included in this work the respective gas phase basicity (GB) values, determined as the deprotonation free energies, were available in the NIST Chemistry WebBook database. ${ }^{[22]}$

The aim of the present work was to experimentally determine the $\mathrm{p} K_{\mathrm{a}}$ values of different $\mathrm{N}$ heterocyclic compounds ${ }^{[23]}$ (Figure 1) in a polar aprotic solvent acetonitrile $(\mathrm{MeCN})$ and compare them with available $\mathrm{p} K_{\mathrm{a}}$ values in water and the gas-phase basicities (GB). Using the $\mathrm{p} K_{\mathrm{a}}$ and $\mathrm{GB}$ values it is possible to elucidate the relations between the basicity of the investigated compounds, their structure and solvent effects. $\mathrm{MeCN}\left(\varepsilon_{r}=35.94\right)^{[24]}$ and $\mathrm{H}_{2} \mathrm{O}$ $\left(\varepsilon_{r}=78.36\right)^{[25]}$ are both polar solvents, but their properties are different. Most importantly, one 
is aprotic and the other is protic solvent, which leads to different extent of solvent effects on the basicity of the investigated compounds. In contrast, the gas phase $\left(\varepsilon_{r}=1\right)$ is the least polar medium and does not induce any solvent or counterion effects on the corresponding intrinsic basicity.

According to the Brønsted-Lowry theory, the basicity of a base $\mathrm{B}_{1}$ in a solvent $\mathrm{S}$ can be defined by the following equation, where $\mathrm{B}_{1} \mathrm{H}^{+}$is the conjugate acid of base $\mathrm{B}_{1}$ :

$$
\mathrm{B}_{1} \mathrm{H}^{+}+\mathrm{S} \rightleftarrows \mathrm{B}_{1}+\mathrm{SH}^{+}
$$

The basicity of a base $\mathrm{B}_{1}$ is expressed as the negative logarithm of the dissociation constant of the conjugate base $\mathrm{B}_{1} \mathrm{H}^{+}$, which is also known as the $\mathrm{p} K_{\mathrm{a}}$ value:

$$
\mathrm{p} K_{a}=-\log \left(K_{a}\right)=-\log \frac{a\left(\mathrm{SH}^{+}\right) \cdot a\left(\mathrm{~B}_{1}\right)}{a\left(\mathrm{~B}_{1} \mathrm{H}^{+}\right)}
$$

In this paper the previously developed spectrophotometric titration method for relative basicity measurements was used. ${ }^{[26]}$ Use of this approach eliminates the necessity of measuring the activity of the solvated proton, $a\left(\mathrm{SH}^{+}\right)$, which is associated with difficulties in a non-aqueous media. Therefore the equilibrium between the two bases, $\mathrm{B}_{1}$ and $\mathrm{B}_{2}$, was studied here:

$$
\mathrm{B}_{1} \mathrm{H}^{+}+\mathrm{B}_{2} \rightleftarrows \mathrm{B}_{2} \mathrm{H}^{+}+\mathrm{B}_{1}
$$

The difference in the basicities, or the relative basicity between the bases $\mathrm{B}_{1}$ and $\mathrm{B}_{2}$, can, therefore, be expressed as the $\Delta \mathrm{p} K_{\mathrm{a}}$ value:

$$
\Delta \mathrm{p} K_{\mathrm{a}}=\mathrm{p} K_{\mathrm{a}}\left(\mathrm{B}_{2} \mathrm{H}^{+}\right)-\mathrm{p} K_{a}\left(\mathrm{~B}_{1} \mathrm{H}^{+}\right)=\log \frac{a\left(\mathrm{~B}_{2} \mathrm{H}^{+}\right) \cdot a\left(\mathrm{~B}_{1}\right)}{a\left(\mathrm{~B}_{1} \mathrm{H}^{+}\right) \cdot a\left(\mathrm{~B}_{2}\right)}
$$




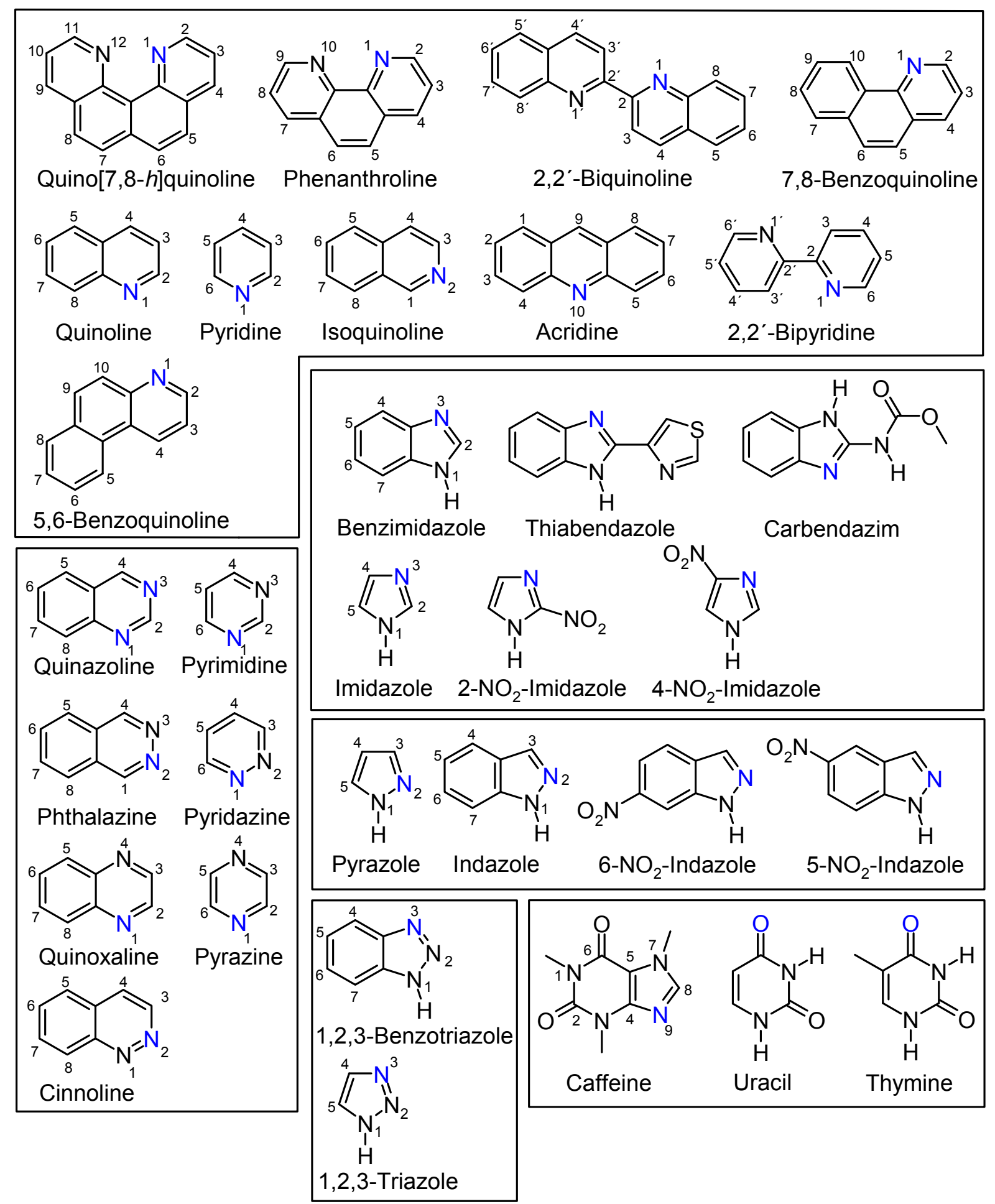

Figure 1. Structures of the heterocyclic compounds for which $\mathrm{p} K_{\mathrm{a}}$ values were evaluated. The favoured protonation sites according to G4MP2 gas phase calculations are highlighted in blue. It was not possible to reliably identify the protonation centre of quinazoline with these calculations. See the SI for protonated forms of uracil and thymine. 


\section{Results}

The basicities of 30 conjugated N-heterocyclic bases (Figure 1), belonging to the families of pyridines, diazines, different 5-member heterocycles and others have been measured in $\mathrm{MeCN}$ solution and each reported as a result of at least two $\Delta \mathrm{p} K_{\mathrm{a}}$ measurements against different reference bases. The $\Delta \mathrm{p} K_{\mathrm{a}}$ measurement results together with the assigned absolute $\mathrm{p} K_{\mathrm{a}}$ values are presented in Table 1 . In addition, the $\mathrm{p} K_{\mathrm{a}}$ values in water and GB values have either been found from the literature or have been computed here. Scheme 1 presents the relationships between the basicities of these compounds in different media. To add to the understanding of the solvent effects, solvation energies of the studied compounds in water and $\mathrm{MeCN}$ have been computed using SMD and COSMO-RS methods. The GB values of the following compounds were additionally computed for comparison: 7,8-benzoisoquinoline $223.2 \mathrm{kcal}$ $\mathrm{mol}^{-1}$, 1,5-diazaphenanthrene $218.6 \mathrm{kcal} \mathrm{mol}^{-1}$, 4,6-diazaphenanthrene $219.7 \mathrm{kcal} \mathrm{mol}^{-1}$, cinnoline $217.4 \mathrm{kcal} \mathrm{mol}^{-1}$, quino[3,4-c] quinoline $220.2 \mathrm{kcal} \mathrm{mol}^{-1}$, quino[7,8-c]isoquinoline $224.5 \mathrm{kcal} \mathrm{mol}^{-1}, 2-\mathrm{NO}_{2}$-pyridine $200.4 \mathrm{kcal} \mathrm{mol}^{-1}, 3-\mathrm{NO}_{2}$-pyridine $201.0 \mathrm{kcal} \mathrm{mol}^{-1}, 4-\mathrm{NO}_{2}$ pyridine $201.5 \mathrm{kcal} \mathrm{mol}^{-1}$. Obtaining estimates of the $\mathrm{p} K_{\mathrm{a}}$ values in water or $\mathrm{MeCN}$ of quinazoline, cinnoline, nitropyridines and quino[7,8- $h]$ quinoline is detailed below.

In order to discuss structural effects on basicity, the standard free energy changes were calculated for a number of isodesmic reactions, and are presented in Table 2.

The absolute $\mathrm{p} K_{\mathrm{a}}$ values in $\mathrm{MeCN}$ were found similarly to previous papers ${ }^{[26]}$ by minimizing the sum of squares of the experimentally measured $\Delta \mathrm{p} K_{\mathrm{a}}$ values and the assigned $\mathrm{p} K_{\mathrm{a}}$ values:

$$
S S=\sum_{i=1}^{n_{m}}\left\{\Delta p K_{a}^{i}-\left[\mathrm{p} K_{\mathrm{a}}\left(\mathrm{HB}_{2}^{+}\right)-\mathrm{p} K_{\mathrm{a}}\left(\mathrm{HB}_{1}^{+}\right)\right]\right\}^{2}
$$

$\Delta \mathrm{p} K_{\mathrm{a}}^{i}$ is the measured difference between the $\mathrm{p} K_{\mathrm{a}}$ values of the conjugate acids of the bases $\mathrm{B}_{2}$ and $\mathrm{B}_{1} \cdot \mathrm{p} K_{\mathrm{a}}\left(\mathrm{HB}_{2}^{+}\right)$and $\mathrm{p} K_{\mathrm{a}}\left(\mathrm{HB}_{1}^{+}\right)$are the absolute $\mathrm{p} K_{\mathrm{a}}$ values for the conjugate acids found by the least squares procedure. The reliability and consistency of the results can be evaluated by using the consistency standard deviation, which is defined by eq 6 :

$$
s=\sqrt{\frac{S S}{n_{m}-n_{c}}}
$$

During this work a total number of measurements $n_{m}=86$ was done to determine the $\mathrm{p} K_{\mathrm{a}}$ values for $n_{c}=30$ compounds, hence the consistency parameter $s=0.04$, indicating good consistency of the data. 
Table 1. Experimental basicities in $\mathrm{MeCN}, \mathrm{H}_{2} \mathrm{O}$, gas phase, and calculated $\mathrm{GB}$ values. Bases measured in this work are given in bold. The rest are reference bases.

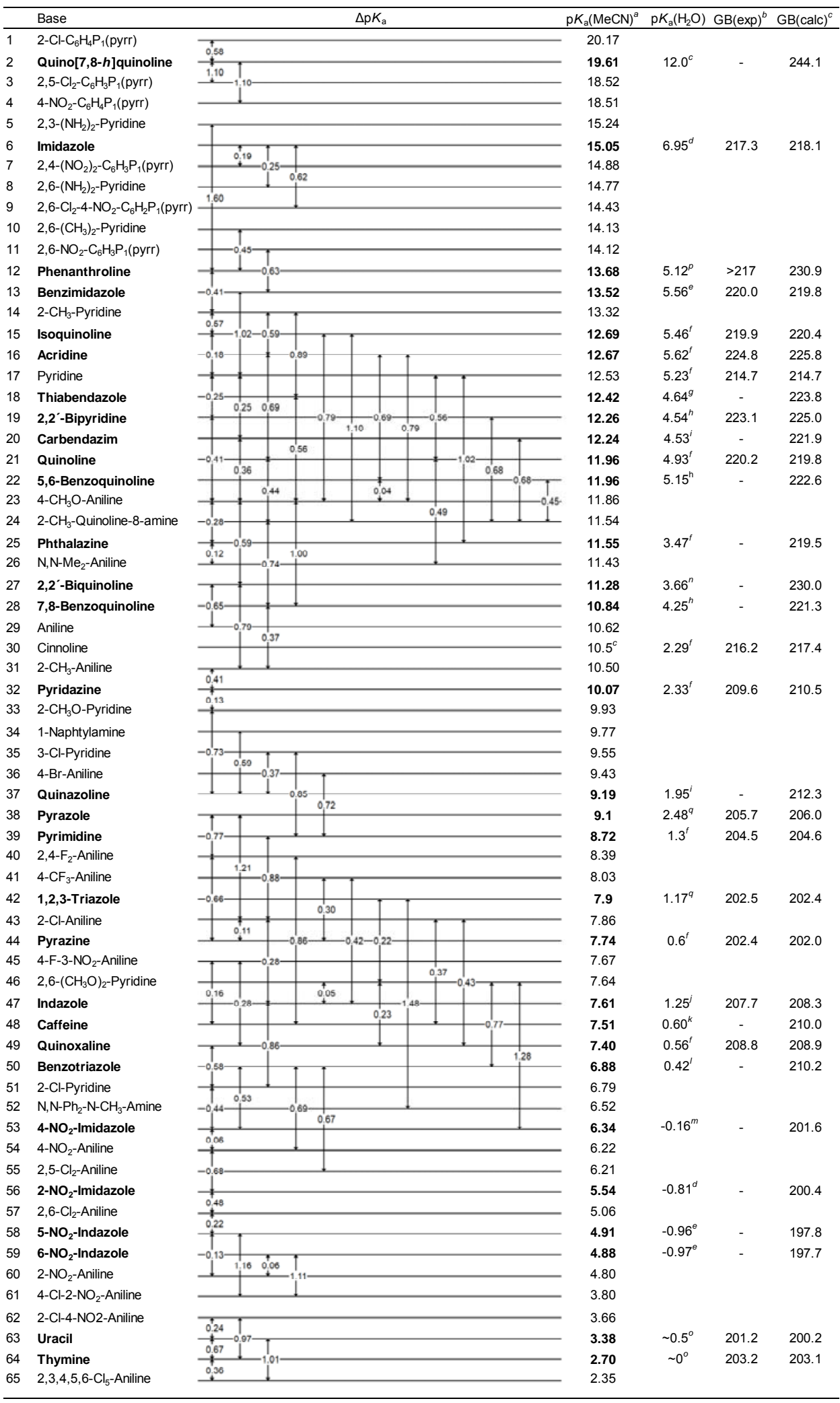

${ }^{a} \mathrm{p} K_{\mathrm{a}}$ values measured in this work are bold and the rest are reference bases. ${ }^{[17,27] b}$ Reference [22]. ${ }^{c} \mathrm{~GB}$ or $\mathrm{p} K_{\mathrm{a}}$ values calculated in this work. ${ }^{d}$ Reference [4]. ${ }^{e}$ Reference [5]. ${ }^{f}$ Reference [6]. ${ }^{g}$ Reference [7]. ${ }^{h}$ Reference [8]. ${ }^{i}$ 
Reference [16]. ${ }^{j}$ Reference [9]. ${ }^{k}$ Reference [10]. ${ }^{l}$ Reference [11]. ${ }^{m}$ Reference [12]. ${ }^{n}$ Reference [13]. ${ }^{o}$ Reference [28]. ${ }^{p}$ Reference [14]. ${ }^{q}$ Reference [15].

Table 2. Isodesmic reaction data. Every reaction was calculated both with neutral molecules (B) and with protonated forms $\left(\mathrm{BH}^{+}\right)$.

\begin{tabular}{|c|c|c|}
\hline Isodesmic reaction & $\begin{array}{c}\Delta G(B) \\
{\left[\mathrm{kcal} \mathrm{mol}^{-1}\right]}\end{array}$ & $\begin{array}{c}\Delta \mathrm{G}\left(\mathrm{BH}^{+}\right) \\
{\left[\mathrm{kcal} \mathrm{mol}^{-1}\right]}\end{array}$ \\
\hline Pyridine + Naphthalene $\rightarrow$ Quinoline + Benzene & -0.9 & -6.0 \\
\hline Pyridine + Naphthalene $\rightarrow$ Isoquinoline + Benzene & 0.1 & -5.6 \\
\hline Quinoline + Naphthalene $\rightarrow$ Acridine + Benzene & 2.7 & -3.3 \\
\hline Pyrazine + Benzene $\rightarrow 2$ Pyridine & -1.9 & -14.6 \\
\hline Pyridazine + Benzene $\rightarrow 2$ Pyridine & -19.6 & -23.7 \\
\hline Pyrimidine + Benzene $\rightarrow 2$ Pyridine & 2.3 & -7.8 \\
\hline Quinoxaline + Naphthalene $\rightarrow 2$ Quinoline & -1.9 & -12.8 \\
\hline Phthalazine + Naphthalene $\rightarrow 2$ Isoquinoline & -18.2 & -19.0 \\
\hline Cinnoline + Naphthalene $\rightarrow$ Isoquinoline + Quinoline & -20.6 & -23.6 \\
\hline Quinazoline + Naphthalene $\rightarrow 2$ Quinoline & 1.5 & -6.1 \\
\hline 7,8-Benzoquinoline $\rightarrow$ Acridine & 6.1 & 1.5 \\
\hline 7,8-Benzoquinoline $\rightarrow$ 5,6-Benzoquinoline & 1.3 & 0.0 \\
\hline 7,8-Benzoquinoline $\rightarrow 7,8$-Benzoisoquinoline & 2.4 & 0.5 \\
\hline Quinoline $\rightarrow$ Isoquinoline & 1.0 & 0.4 \\
\hline Imidazole + Naphthalene $\rightarrow$ Benzimidazole + Benzene & -2.4 & -4.2 \\
\hline Pyrazole + Naphthalene $\rightarrow$ Indazole + Benzene & 1.5 & -0.8 \\
\hline $\begin{array}{l}\text { 1,2,3-Triazole }+ \text { Naphthalene } \rightarrow \text { Benzotriazole }+ \\
\text { Benzene }\end{array}$ & 5.4 & -2.4 \\
\hline Pyrazole $\rightarrow$ Imidazole & -10.9 & -23.0 \\
\hline Indazole $\rightarrow$ Benzimidazole & -14.8 & -26.4 \\
\hline $\begin{array}{l}\text { Quino[7,8- } h] \text { quinoline }+ \text { Naphthalene } \rightarrow 2 \text { 7,8- } \\
\text { Benzoquinoline }\end{array}$ & -11.3 & 11.6 \\
\hline Phenanthroline + Benzene $\rightarrow 2$ Quinoline & -1.2 & 9.8 \\
\hline Phenanthroline + Benzene $\rightarrow 2$ Isoquinoline & 0.7 & 11.2 \\
\hline Quino[7,8-h]quinoline $\rightarrow$ Quino[3,4-c]quinoline & -2.7 & 21.3 \\
\hline Quino[7,8-h]quinoline $\rightarrow$ Quino[7,8-c]isoquinoline & -6.6 & 13.1 \\
\hline 2,2'-Bipyridine $($ anti $) \rightarrow 2,2^{\prime}$-Bipyridine $(s y n)$ & 5.5 & -6.7 \\
\hline $2,2^{\prime}$-Biquinoline $($ anti $) \rightarrow 2,2^{\prime}$-Biquinoline $($ syn $)$ & 5.9 & -5.9 \\
\hline 1,5-Diazaphenanthrene $\rightarrow$ Phenanthroline & 5.0 & -7.3 \\
\hline 4,6-Diazaphenanthrene $\rightarrow$ Phenanthroline & 2.9 & -8.3 \\
\hline
\end{tabular}


Scheme 1. Relationships between the basicities of some of the studied compounds in different media. ${ }^{a}$

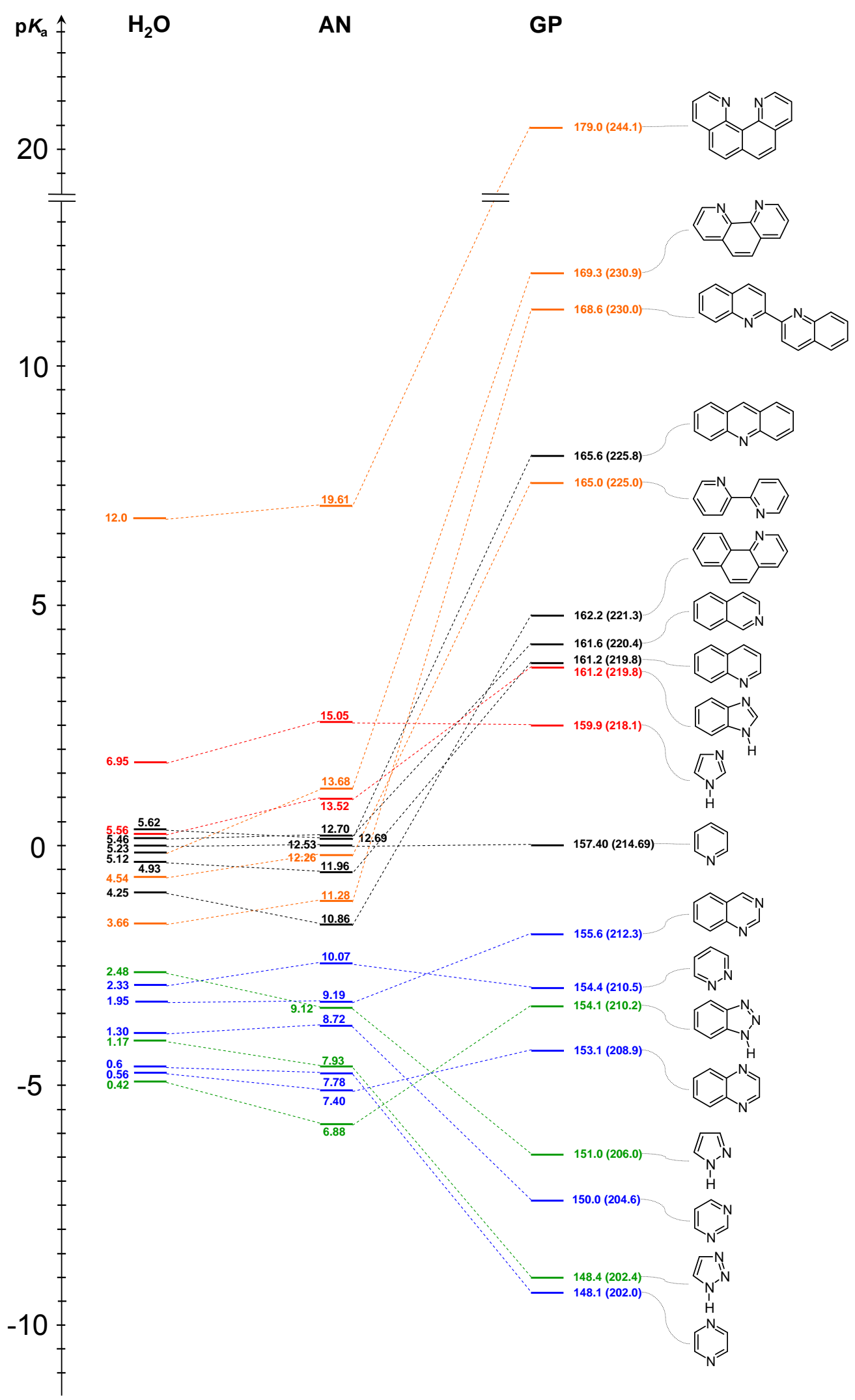

${ }^{a}$ In $\mathrm{MeCN}$ and $\mathrm{H}_{2} \mathrm{O}: \mathrm{p} K_{\mathrm{a}}$ values. In the gas phase the first value is $\mathrm{p} K_{\mathrm{a}}$ value (to allow direct comparison with solution data) and the GB value in $\mathrm{kcal} \mathrm{mol}^{-1}$ is in parentheses. Colors by derivatives: pyridine - black, diazines - blue, imidazole - red, other 5-member rings - green, large molecules forming IMHB - orange. 
Quinazoline. The commonly cited, directly measurable experimental value for the aqueous $\mathrm{p} K_{\mathrm{a}}$ of quinazoline $\left(\mathrm{p} K_{\mathrm{a}}=3.51^{[6]}\right)$ actually corresponds to a more complex equilibrium, involving covalent hydration of quinazoline. ${ }^{[29]}$ A correct experimentally measured aqueous $\mathrm{p} K_{\mathrm{a}}$ corresponding to the $\mathrm{p} K_{\mathrm{a}}$ definition (eq 1 ) is $1.95 .^{[16]}$ This value is in good agreement with our calculated $\mathrm{p} K_{\mathrm{a}}$ values 1.7...1.9 (depending on the method).

Cinnoline. Because cinnoline was not commercially available its $\mathrm{p} K_{\mathrm{a}}$ value in $\mathrm{MeCN}$ was not experimentally determined. The value has been calculated using the COSMO-RS approach and empirically corrected. The resultant $\mathrm{p} K_{\mathrm{a}}(\mathrm{MeCN})$ value is $10.5 \pm 0.3$.

Nitro-substituted pyridines. The basicities of 2-, 3-, and 4-nitropyridine have been obtained using the correlation between the $\mathrm{p} K_{\mathrm{a}}$ data in water and $\mathrm{MeCN}$ and/or empirically corrected COSMO-RS calculations. Accordingly, the $\mathrm{p} K_{\mathrm{a}}(\mathrm{MeCN})$ values for 2-, 3- and 4-nitropyridine are $3.8 \pm 0.4,7.14 \pm 0.13$, and $7.85 \pm 0.13$, respectively. The aqueous $\mathrm{p} K_{\mathrm{a}}$ of 2-nitropyridine has been estimated as $-2.5 \pm 0.5$.

Quino[7,8-h]quinoline. The aqueous $\mathrm{p} K_{\mathrm{a}}$ value of quino[7,8-h]quinoline (QQ) was impossible to obtain experimentally due to the extremely low solubility of this compound in water. The value has been estimated in two ways: using the relationships between experimental $\mathrm{p} K_{\mathrm{a}}$ data in acetonitrile and water, and with the aid of empirically corrected COSMO-RS calculations. The results are summarized below. Please see the Supporting Information for more details.

Using a simple linear correlation between the $\mathrm{p} K_{\mathrm{a}}$ values in water and $\mathrm{MeCN}$ (as depicted in Figure 3) for prediction is not expected to give accurate results in the case of QQ. On one hand, unlike other molecules studied in this work, QQ chelates the proton and effectively prevents its interaction with surrounding media (phenanthroline, which may also be considered chelating, does not hinder the proton-solvent interaction to the same extent as QQ). On the other hand, QQ is by far the most basic heterocycle studied in this work, meaning that it will be a far-away point in the correlation analysis, thereby additionally decreasing the reliability of prediction. Amongst the bases with available accurate $\mathrm{p} K_{\mathrm{a}}$ values in both water and $\mathrm{MeCN}, 1,8$-bis(dimethylamino)naphthalene (DMAN) is the most similar to QQ in the context of this discussion. Firstly, it is a very strong base $\left(\mathrm{p} K_{\mathrm{a}}(\mathrm{MeCN})=18.62^{[17]}\right.$ and $\mathrm{p} K_{\mathrm{a}}$ (water) $=12.1^{[30]}$ ); secondly, because of extensive charge delocalization and steric shielding of the protonation centre the cation of DMAN, similarly to protonated QQ, lacks the hotspots of localized excess charge (see Figure S2 in the SI). Such effective chelation enhances the intrinsic basicity of a base, but significantly decreases solvent stabilization of its 
cation, as it was recently demonstrated for some pyridine-supported bicyclic guanidines. ${ }^{[31]}$ This basicity-decreasing effect is probably more pronounced in media with strong hydrogenbond-acceptor properties $(\mathrm{MeCN})$ rather than amphiprotic solvents $\left(\mathrm{H}_{2} \mathrm{O}\right)$. On the other hand, as the protonation centres of rigid chelating bases are less accessible to solvent molecules, compared to non-chelating molecules, the solvent stabilization of their neutral forms is also weaker. Such basicity-promoting effect is more significant in hydrogen-bond-donating solvents. Supplementing the correlation in Figure 3 with several strong bases, including DMAN, supports the above arguments. Although the linear range extends to high $\mathrm{p} K_{\mathrm{a}}$ regions, DMAN, the most effective chelating base in the set, stands out with lower difference of $\mathrm{p} K_{\mathrm{a}}(\mathrm{MeCN})$ and $\mathrm{p} K_{\mathrm{a}}$ (water) than most other bases. Assuming the $\Delta \mathrm{p} K_{\mathrm{a}}(\mathrm{MeCN}$-water) of QQ is similar to that of DMAN (6.5 units), the aqueous $\mathrm{p} K_{\mathrm{a}}$ of QQ is expected to be around 13.1. Comparisons between other chelating and non-chelating strong bases also suggest that the $\mathrm{p} K_{\mathrm{a}}$ (water) of QQ is around 13 .

COSMO-RS calculations were carried out using the cluster-continuum approach: one water molecule was explicitly added to every neutral and protonated base. The set of 16 bases relatively similar to QQ was used to verify and correct the computational $\mathrm{p} K_{\mathrm{a}}$ values. The COSMO-RS results were found to correlate well with the experimental data, and the empirical correction equation was obtained. The chelating and non-chelating bases were described well by the same regression equation. The empirically corrected calculated $\mathrm{p} K_{\mathrm{a}}$ of QQ is 10.3 with standard uncertainty 0.7 .

Taking into account both estimates and considering the somewhat more reliable comparison approach described above, the recommended aqueous $\mathrm{p} K_{\mathrm{a}}$ value of QQ is thus $12.0 \pm 1.5$.

Comparison of spectrophotometric and differential potentiometric methods. In order to validate the used spectrophotometric $\mathrm{p} K_{\mathrm{a}}$ measurement method and the recently developed differential potentiometric method for comparison of absolute $\mathrm{pH}$ values in different solutions, the $\Delta \mathrm{p} K_{\mathrm{a}}$ values of 5 base pairs were measured using differential potentiometry. Table 3 presents the results. The root mean square (RMS) difference reveals good agreement between the methods, demonstrating the mutual consistency of these methods based on fundamentally different principles. This can be regarded as evidence of validity of both methods. 
Table 3. Comparison of the results of spectrophotometric and potentiometric measurements.

\begin{tabular}{|l|l|c|c|c|}
\hline Base 1 & Base 2 & $\begin{array}{c}\Delta \mathrm{p} K_{\mathrm{a}}{ }^{a} \\
\text { (spectrophotometric) }\end{array}$ & $\begin{array}{c}\Delta \mathrm{p} K_{\mathrm{a}}{ }^{a} \\
\text { (potentiometric) }\end{array}$ & Difference \\
\hline Quinoline & Isoquinoline & 0.73 & 0.70 & 0.03 \\
\hline Quinazoline & Isoquinoline & 3.50 & 3.56 & -0.06 \\
\hline Quinazoline & 5,6-benzoquinoline & 2.77 & 2.85 & -0.08 \\
\hline 5,6-benzoquinoline & Acridine & 0.71 & 0.72 & -0.01 \\
\hline Quinoline & Acridine & 0.71 & 0.82 & -0.11 \\
\hline & & & $\begin{array}{c}\text { RMS } \\
\text { difference: }\end{array}$ & $\mathbf{0 . 0 9}$ \\
\hline
\end{tabular}

${ }^{a} \Delta \mathrm{p} K_{\mathrm{a}}=\mathrm{p} K_{\mathrm{a}}\left(\right.$ Base 2) $-\mathrm{p} K_{\mathrm{a}}($ Base 1$)$. With potentiometry the $\Delta \mathrm{p} K_{\mathrm{a}}$ was measured by directly comparing the solutions of the bases. With spectrophotometry the $\Delta \mathrm{p} K_{\mathrm{a}}$ was calculated as differences of the $\mathrm{p} K_{\mathrm{a}}$ values of the bases from Table 1 .

\section{Discussion}

In the following discussion, the various structural effects on the basicity, elucidated from the available data, are addressed. The compounds presented in this paper can be divided into subfamilies based on the structural features. The studied derivatives of six-membered heterocycles can be further divided into pyridines, diazines, and compounds containing several pyridine rings. In case of five-membered heterocycles, derivatives of imidazole, pyrazole and 1,2,3-triazole were studied in this work. The basicities of the heterocycles inside these groups can be compared in different media because of the structural similarities.

As a generalization, it can be said that the main factors determining the basicity trends in the gas phase are the ability of delocalizing the cationic charge across as large a $\pi$-system as possible, and the differences between steric effects operating in the neutral and cationic forms of the compound. The same factors operate in solution (with the large $\pi$-system now being somewhat less important) and in addition, solvation phenomena (first of all possible steric hindrance to solvation) are important.

\section{Effect of hydrogen in peri position}

The collected data show that a hydrogen atom in peri position with respect to the protonation centre (e.g. hydrogen in position 8 in the case of quinoline, see Figure 1) has a weak stabilizing interaction with the lone pair of the nitrogen in the neutral form of the respective heterocycle and causes steric hindrance to the solvation of its protonated form, thus having a basicity-decreasing effect. However, the peri effect on basicity may be overshadowed by 
other factors, e.g. improvement in the charge delocalization capability by the same structural fragment that causes peri effect, therefore a fine interplay of these two opposing effects determines the basicity trends in a family of related systems.

As an example, the pyridine derivatives quinoline and isoquinoline both have by more than 5 $\mathrm{kcal} \mathrm{mol}^{-1}$ higher basicity than pyridine in the gas phase, because of the larger size of the molecular framework into which the cation charge is delocalized. ${ }^{[32]}$ However, in both studied solvents the basicity order is isoquinoline $>$ pyridine $>$ quinoline, despite the very similar structures of the two benzo-derivatives. It has been previously reported that this kind of difference in basicity comes from the peri steric effect. ${ }^{[33]}$ Peri effect is present in quinoline, making it somewhat less basic than pyridine. However, this effect is absent in isoquinoline, which is $0.17 \mathrm{p} K_{\mathrm{a}}$ units more basic than pyridine in $\mathrm{MeCN}$ and 0.23 units in water. Without the peri effect the main factor accounting for the higher basicity is the additional aromatic ring stabilizing the protonated isoquinoline cation through the more extensive delocalization of the positive charge. As in solution, isoquinoline is more basic than quinoline in the gas phase, by $0.6 \mathrm{kcal} \mathrm{mol}^{-1}$. Comparison of quinoline and isoquinoline using the isodesmic reactions approach (eq 7 and Table 2) reveals that the lower GB of quinoline is caused, first of all, by the stronger stabilization of the non-protonated quinoline molecule, thereby supporting the above mentioned interpretation of peri effect.

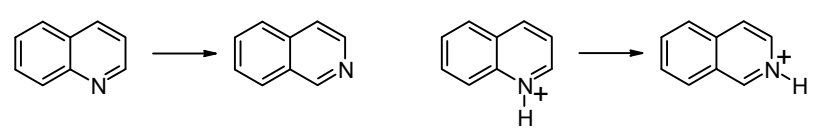

Accordingly, the peri steric effect is also present in acridine, and to a greater extent. Nevertheless, the stabilization of protonated acridine through extensive charge delocalization by three aromatic rings overcomes this effect in all three media. Acridine beats isoquinoline by $5.4 \mathrm{kcal} \mathrm{mol}^{-1}$ in the gas phase and has about the same basicity in $\mathrm{MeCN}$ (but is $c a 0.7 \mathrm{p} K_{\mathrm{a}}$ units stronger base than quinoline in $\mathrm{MeCN}$ ). In $\mathrm{H}_{2} \mathrm{O}$, the $\mathrm{p} K_{\mathrm{a}}$ value for acridine is by 0.16 units higher than for isoquinoline, meaning that either the stronger stabilizing effect of the additional aromatic ring for the acridinium cation predominates or, alternatively, the stabilization of neutral acridine by hydrogen bond interactions from $\mathrm{H}_{2} \mathrm{O}$ is weaker.

When comparing acridine to its isomer 7,8-benzoquinoline it appears that the latter is a weaker base by $4.6 \mathrm{kcal} \mathrm{mol}^{-1}$ in the gas phase, by $1.82 \mathrm{p} K_{\mathrm{a}}$ units in $\mathrm{MeCN}$ and 1.37 units in water. This may be caused by the joint effect of stabilization of the neutral base by the $\mathrm{H}$ atom in position 10 , likely steric hindrance to protonation by the same $\mathrm{H}$ atom, and also by the 
dramatic hindrance to cation solvation caused by adding the third ring. The additional charge delocalization ability of the third ring is weak because it is far from the basicity centre.

Analysis of isodesmic reactions vs. different isomers of 7,8-benzoquinoline (eq 8 to 10) reveals the additional stabilization of the neutral 7,8-benzoquinoline compared to its isomers between 1 and $6 \mathrm{kcal} \mathrm{mol}^{-1}$ (the highest vs acridine) while the protonated 7,8-benzoquinoline is also more stable (by $1.5 \mathrm{kcal} \mathrm{mol}^{-1}$ ) than protonated acridine and is of similar stability with the remaining two compounds. This demonstrates that stabilization of the neutral base by interaction of the nitrogen lone pair with $\mathrm{H}$ atom in position 10 is an important factor but steric hindrance to protonation is not, or is overshadowed by some other electronic effects.

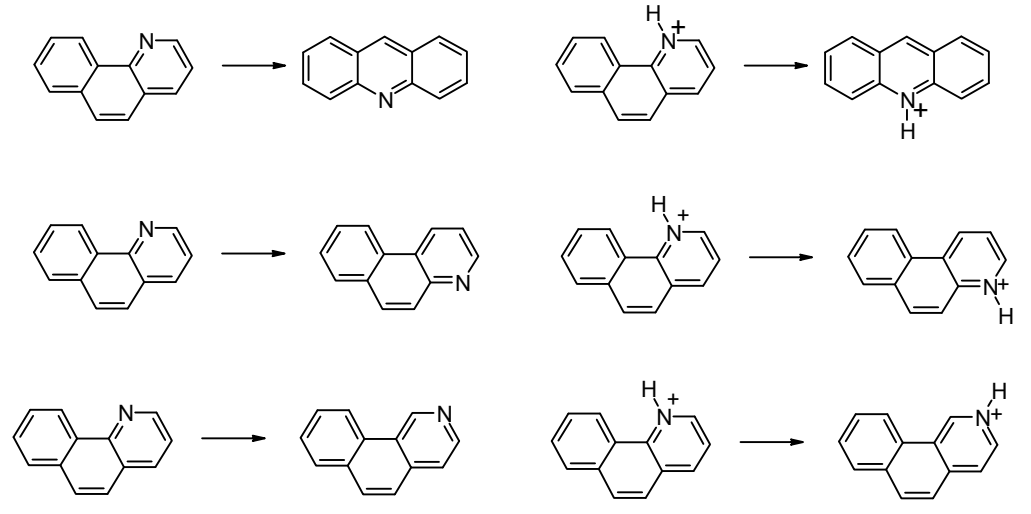

\section{Effect of intramolecular hydrogen bond in protonated bases}

Phenanthroline, quino[7,8-h]quinoline (QQ), 2,2'-bipyridine and 2,2'-biquinoline are all compounds that can form chelating complexes with different metal ions due to two suitably positioned $\mathrm{N}$ atoms in their structure. ${ }^{[34-36]}$ The chelating ability of these molecules allows them to form intramolecular hydrogen bonds (IMHB) in their protonated forms. One indication for IMHB is the elongation of the $\mathrm{NH}$ bond in the protonated base. The $\mathrm{NH}$ bond lengths (in the gas phase) in the protonated forms of phenanthroline, QQ, 2,2'-bipyridine and 2,2'-biquinoline are $1.023,1.058,1.029$ and $1.026 \AA$, respectively, as opposed to 1.014-1.015 $\AA$ in pyridine, quinoline and isoquinoline. Our data also confirms that the IMHB increases the gas phase basicity of these compounds compared to their counterparts without this kind of stabilizing bond.

2,2'-Bipyridine and 2,2'-biquinoline in their neutral forms predominantly assume anti conformations in the gas phase (as seen in Figure 1). According to the calculations, upon protonation both molecules rotate around the central $\mathrm{C}-\mathrm{C}$ bond to allow the formation of the 
$\mathrm{N}-\mathrm{H} \cdots \mathrm{N}$ hydrogen bond. Comparison of such hydrogen-bonded cations with the protonated forms still in "anti" conformations (see also Table 2) shows a $6.7 \mathrm{kcal} \mathrm{mol}^{-1}$ effect of IMHB formation for 2,2'-bipyridine and a $5.9 \mathrm{kcal} \mathrm{mol}^{-1}$ for 2,2'-biquinoline, which makes them by 10.3 and $10.2 \mathrm{kcal} \mathrm{mol}^{-1}$ more basic in the gas phase than pyridine and quinoline, respectively. However, in solvents the $\mathrm{p} K_{\mathrm{a}}$ order of 2,2'-bipyridine and 2,2'-biquinoline is reversed compared to the gas phase and these bases are less basic than pyridine and quinoline, respectively. Apparently the electron-withdrawing effect of the quinolinyl and pyridyl groups is stronger than the stabilizing effect of the IMHBs, which in $\mathrm{MeCN}$ and water are rather weak because of efficient competition from solvent molecules.

Thiabendazole and carbendazim have GB values similar to 2,2'-bipyridine and IMHB is expected in the protonated forms. Both protonated structures have two structurally very similar NH bonds differing only by the presence of an IMHB. The lengths of the NH bonds in thiabendazole are $1.008 \AA$ and $1.012 \AA$ and in carbendazim $1.009 \AA$ and $1.016 \AA$. The difference in length indicates that IMHB in the protonated forms plays a role in their basicity. However, the energetic contribution cannot be obtained as due to the symmetrical structure of the protonated benzimidazole moiety, it is not possible to envisage a realistic conformer without IMHB.

Quino[7,8-h]quinoline and phenanthroline are the most basic of all the heterocycles studied in this work in the gas phase, with GB values of $244.1 \mathrm{kcal} \mathrm{mol}^{-1}$ and $230.9 \mathrm{kcal} \mathrm{mol}^{-1}$, respectively. The very high basicity of these compounds (especially quino[7,8-h]quinoline) is caused by the extensive delocalization of the positive charge of the protonated species into the aromatic rings and also by the formation of stabilizing IMHBs.

In the protonated forms of these compounds there are no possibilities to remove the IMHB with simple rotations around a chemical bond, so two different approaches to estimate its effect were used: firstly, the GB values for IMHB-incapable isomers were calculated for comparison (Figure 2) and secondly, isodesmic reactions 11 and 12 were used.

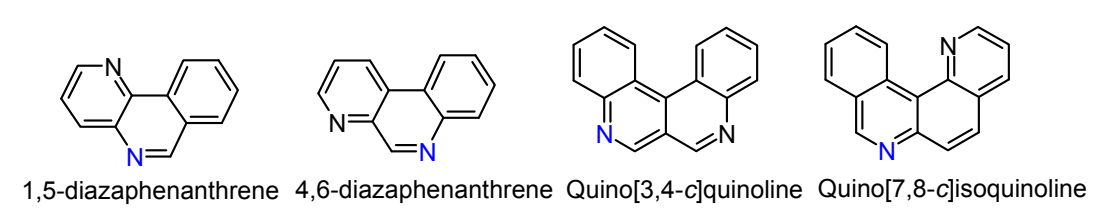

Figure 2. Molecules used in calculations of the effects of IMHBs. The favoured protonation sites according to G4MP2 gas phase calculations are highlighted in blue.

For phenanthroline, we selected 1,5-diazaphenanthrene and 4,6-diazaphenanthrene for comparison. In both isomers the nitrogen atoms are separated from each other by three 
chemical bonds as in phenanthroline. The aim was to keep all basicity-determining factors, except IMHB, as similar to phenanthroline as possible. The only effect that cannot be avoided this way is the effect of repulsion from the peri hydrogen in the protonated forms of the isomers, but this effect is small as was explained above. Comparison of GB values of these isomers indicates that the joint basicity-increasing effect of lone pair repulsion in the neutral and IMHB in the protonated form on the GB value of phenanthroline is 11.2 to 12.3 $\mathrm{kcal} \mathrm{mol}^{-1}$ (found as GB differences between phenanthroline and the two isomers). Of this 7.3 to $8.3 \mathrm{kcal} \mathrm{mol}^{-1}$ is the GB increasing effect of IMHB (see Table 2).
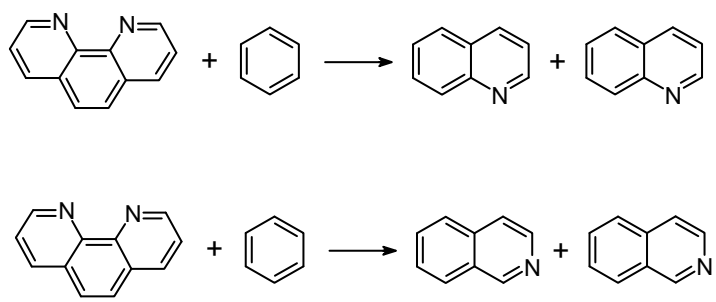
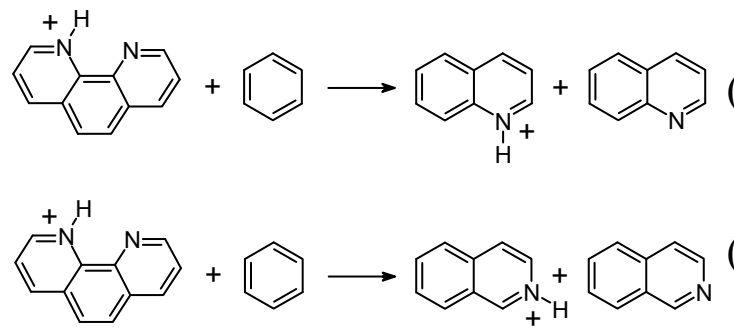

Another possibility of estimating the energetic effect of IMHB on the GB of phenanthroline is to consider the $\Delta G$ values of isodesmic reactions 11 and 12 with cationic forms. Besides the IMHB energy, these reaction $\Delta G$ values include a repulsion contribution from the peri hydrogen (which is a small effect), and a contribution attributed to charge compression on going from a three-ring cation to a two-ring cation, which on the analogy with acridine (see below) can be estimated as $c a 3 \mathrm{kcal} \mathrm{mol}^{-1}$. The overall effect of IMHB estimated this way is $7-8 \mathrm{kcal} \mathrm{mol}^{-1}$, which is in excellent agreement with the previous approach.

In liquid phase, however, the effect of IMHB in rigid heterocycles is not straightforward. On one hand IMHB increases the intrinsic basicity. On the other hand, it reduces the solvent stabilization of the cation by obstructing the interaction of the added proton and the acceptor atom with solvent molecules. In both $\mathrm{H}_{2} \mathrm{O}$ and $\mathrm{MeCN}$ phenanthroline has a much lower $\mathrm{p} K_{\mathrm{a}}$ values than would be expected from its GB value: 5.12 and 13.7, respectively. This means that phenanthroline has by about one $\mathrm{p} K_{\mathrm{a}}$ unit higher basicity than pyridine in $\mathrm{MeCN}$ and is slightly less basic than pyridine in $\mathrm{H}_{2} \mathrm{O}$. Solvation energies for both molecules and their protonated forms in $\mathrm{H}_{2} \mathrm{O}$ and $\mathrm{MeCN}$ can be used to interpret these results. Compared to pyridine, the solvation energy of neutral phenanthroline is by $6.2-8.3 \mathrm{kcal} \mathrm{mol}^{-1}$ (depending on computational approach, see the SI) more negative in $\mathrm{H}_{2} \mathrm{O}$ and $7.6-8.0 \mathrm{kcal} \mathrm{mol}^{-1}$ more negative in $\mathrm{MeCN}$. The solvation energy of the protonated phenanthroline is by about 9.7 $11.5 \mathrm{kcal} \mathrm{mol}^{-1}$ and $7.7-9.0 \mathrm{kcal} \mathrm{mol}^{-1}$ less negative in $\mathrm{H}_{2} \mathrm{O}$ and $\mathrm{MeCN}$, respectively, when 
compared to protonated pyridine. According to these energy differences the basicity of pyridine hugely benefits from solvation compared to phenanthroline both in neutral and in cationic form, so the high intrinsic basicity of phenanthroline is reduced to the vicinity of pyridine both in $\mathrm{H}_{2} \mathrm{O}$ and $\mathrm{MeCN}$.

To quantify the intramolecular hydrogen bond effect in quino[7,8- $h$ ]quinoline the GB values for its isomers quino[3,4-c] quinoline $\left(220.2 \mathrm{kcal} \mathrm{mol}^{-1}\right)$ and quino[7,8-c]isoquinoline $(224.5$ $\mathrm{kcal} \mathrm{mol}^{-1}$ ) were calculated. The nitrogen atoms are separated by four chemical bonds in these isomers as in quino[7,8-h]quinoline. Our results demonstrate that the net GB increasing effect of IMHB in protonated quino[7,8-h]quinoline and the lone pair repulsion in the neutral form is around $20-24 \mathrm{kcal} \mathrm{mol}^{-1}$. Of this 13 to $21 \mathrm{kcal} \mathrm{mol}^{-1}$ is due to IMHB. These effects are much larger than in case of the previously mentioned compounds and are in good agreement with the above mentioned highest elongation of the $\mathrm{NH}$ bond in the protonated base.

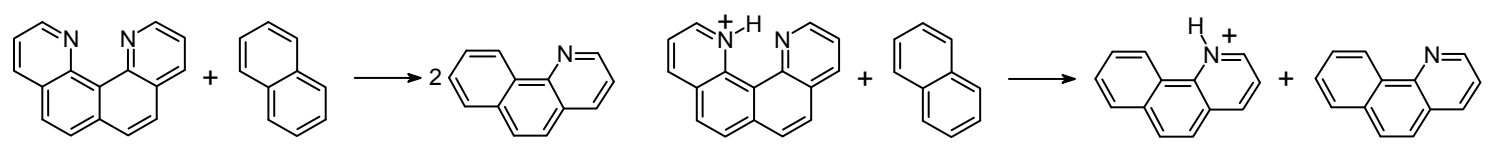

The energetic effect of the IMHB estimated from the $\Delta G$ value of the isodesmic reaction 13 amounts to $11.6 \mathrm{kcal} \mathrm{mol}^{-1}$. Out of the three estimates of IMHB energy the highest one, obtained with quino[3,4-c] quinoline, is artificially increased by the repulsion of the facing hydrogen atoms in the 5 and $5^{\prime}$ positions. Thus, we estimate the energetic effect of IMHB in quino[7,8-h]quinoline as $12 \mathrm{kcal} \mathrm{mol}^{-1}$.

Similarily to the gas phase, quino[7,8-h]quinoline has also remarkably high $\mathrm{p} K_{\mathrm{a}}$ values in $\mathrm{H}_{2} \mathrm{O}$ and $\mathrm{MeCN}-12.0$ and 19.61, respectively. The solvation energy of neutral quino[7,8h] quinoline is by $5.6-6.7 \mathrm{kcal} \mathrm{mol}^{-1}$ more negative in $\mathrm{H}_{2} \mathrm{O}$ and $9.0-10.0 \mathrm{kcal} \mathrm{mol}^{-1}$ more negative in $\mathrm{MeCN}$ compared to pyridine. The protonated quino[7,8- $h]$ quinoline has by $15.1-$ $17.2 \mathrm{kcal} \mathrm{mol}^{-1}$ less negative solvation energy in $\mathrm{H}_{2} \mathrm{O}$ and by 10.6 - 13.0 less negative solvation energy in $\mathrm{MeCN}$. The solvation energies show that, similarly to phenanthroline, pyridine hugely benefits from solvation compared to quino[7,8-h]quinoline. Also, the protonation site of quino[7,8-h]quinoline is much more sterically shielded than phenanthroline's protonation site, so the solvent molecules are almost unable to form any hydrogen bonds with it. However, since the intrinsic basicity of quino[7,8-h]quinoline is so high, in solution it still beats pyridine by a wide margin. 


\section{The effect of the ring size (5- vs 6-membered rings)}

5-member aromatic heterocycles have a higher overall electron density compared to 6member aromatic heterocycles: both have $6 \pi$-electrons, but the ring size of 5 -member heterocycles is smaller. In part for this reason, out of all the molecules studied, the 5membered imidazole is the most basic single-ring heterocycle in the gas phase, beating all of the studied six-member heterocycles without fused aromatic rings. Additionally, this is likely due to the fact that neutral imidazole is more strained than the 6-member-rings. I.e. the initial base is destabilized, while some of the strain is relieved upon the protonation. Both effects contribute to the basicity enhancement producing a symmetrical imidazolium cation. These effects are also operational in pyrazole, where, however, the conjugate acid is destabilized through steric interactions as it suffers from the close vicinity of the two $\mathrm{N}-\mathrm{H}$ fragments. This becomes the dominant effect, which is absent in the analogous 6-membered pyridazine, thus making the latter $4.5 \mathrm{kcal} \mathrm{mol}^{-1}$ more basic in the gas phase. The same trend in the gas phase is maintained upon fusing an additional benzene ring to these monocycles: benzimidazole is more basic than quinazoline, while 5-membered indazole is still less basic than both 6membered phthalazine and cinnoline. It is also worth reiterating that the basicity of both quinazoline and cinnoline is further reduced because of the peri effect, which, for example, makes cinnoline $2.1 \mathrm{kcal} \mathrm{mol}^{-1}$ less basic than the analogous phthalazine. Interestingly, the same basicity order is also observed in both solution phases. Imidazole is a stronger base than pyrimidine in both $\mathrm{MeCN}$ and water, the same holds for their benzo-derivatives benzimidazole and quinazoline. Analogously, 5-membered pyrazole and indazole are less potent bases than pyridazine and phthalazine/cinnoline in solution phases. As a general conclusion we could say that 5-membered heterocycles involving two nitrogen atoms are more basic than the analogous 6-membered systems in all studied phases, because in 5membered heterocycles the second nitrogen atom increases the electron density in the ring by donating two electrons to the ring (for making up the aromatic sextet) thereby increasing basicity, while in 6-membered ring the second nitrogen atom acts essentially as an electronwithdrawing group, thereby reducing the basicity. On the other hand, if the two nitrogen atoms are located next to each other, the latter effect is outperformed by the steric hindrance of the two $\mathrm{N}-\mathrm{H}$ fragments in the 5-membered systems, thus making them less basic than their 6-membered counterparts, where this effect is absent. 


\section{Fusion of benzene ring to a single-ring heterocycle}

The effect of fusion of an additional aromatic ring to a single-ring heterocycles is two-fold. On one hand, it increases the volume for distributing the positive charge in the cation, which usually results in promoting the gas-phase basicity, while reducing the solution phase basicity constants. On the other hand, the fused benzene ring may act as electron-withdrawing or electron-donating group, depending on the relative overall electronegativities of the initial heterocycle and the fusion position of the added ring. Another possible effect is the peri effect that was described above.

Specifically the effect of distributing the positive charge into a larger volume by fusing one additional benzene ring to the structure can be seen from the isodesmic reactions 14 (and its analogue with isoquinoline), 15 and 16 . The stabilizing effect amounts to $6.0 \mathrm{kcal} \mathrm{mol}^{-1}$ in the case of pyridine $\rightarrow$ quinoline, $5.6 \mathrm{kcal} \mathrm{mol}^{-1}$ in the case of pyridine $\rightarrow$ isoquinoline and 3.3 $\mathrm{kcal} \mathrm{mol}^{-1}$ in the case of quinoline $\rightarrow$ acridine.

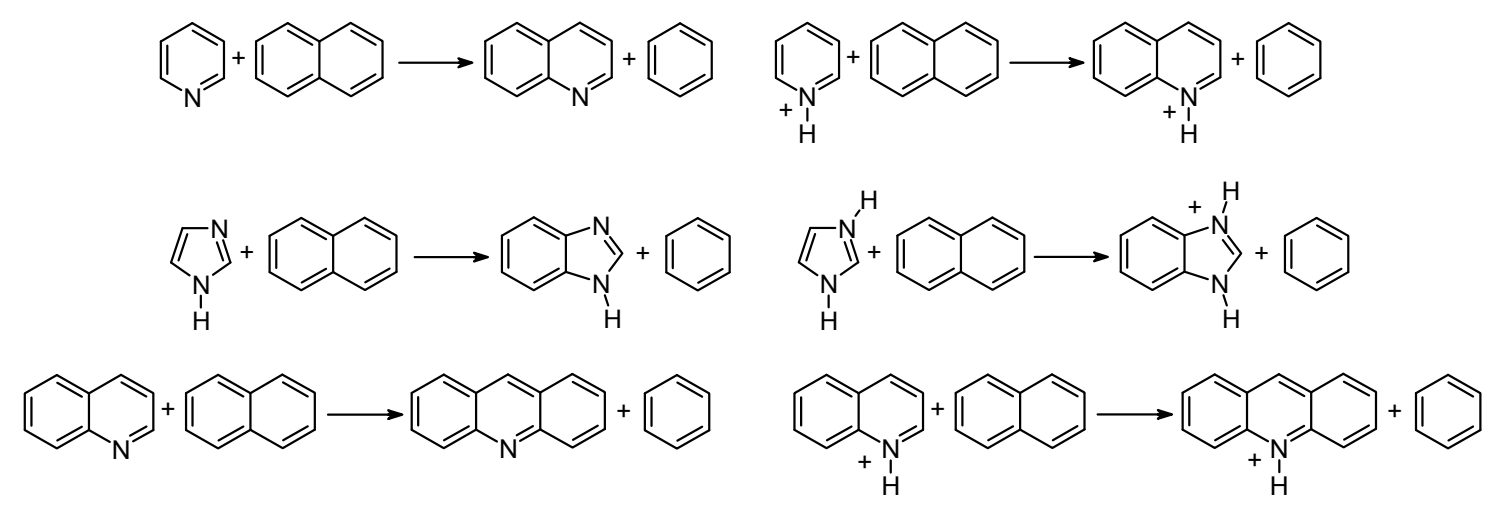

Comparing pyridine with its benzene ring fused derivatives quinoline and isoquinoline shows that in the gas phase the benzo-derivatives are by 5.1 and $5.7 \mathrm{kcal} \mathrm{mol}^{-1}$ more basic. In both solvents, however, the effect of improved charge delocalization is overshadowed by other factors (e.g steric hindrance to cation solvation caused by peri effect), so the three compounds demonstrate rather similar $\mathrm{p} K_{\mathrm{a}}$ values and basicity order isoquinoline $>$ pyridine $>$ quinoline. Similar situation is observed in the case of 6-membered diazines, where the addition of benzene ring leads to uniform basicity increase in the gas phase: benzodiazines are more basic than corresponding diazines by $7-9 \mathrm{kcal} \mathrm{mol}^{-1}$. Phthalazine and quinazoline are more basic than the corresponding diazines also in solution (by 1.5 and $0.5 \mathrm{p} K_{\mathrm{a}}$ units in $\mathrm{MeCN}$ and 1.1 and 0.7 units in water, respectively). As expected, the difference in the gas phase is larger, because in the absence of solvation the effect of additional charge delocalization possibility is 
decisive. However, in the pyrazine-quinoxaline pair the benzo-derivative is slightly less basic (by $0.38 \mathrm{p} K_{\mathrm{a}}$ units) than the single-ring compound in $\mathrm{MeCN}$ and has similar basicity in $\mathrm{H}_{2} \mathrm{O}$ (difference 0.04 units). The differences in relative computational solvation energies are not large enough to undoubtedly elucidate the cause of these trends.

Fusion of 5-membered heterocycles with benzene, in addition to improving charge delocalization in the protonated base, also leads to an overall decrease of electron density in the 5-member ring (incl. at the protonation centre) of the neutral base, which has a basicitydecreasing effect. Isodesmic reaction 15 shows that both the neutral and protonated benzimidazole is more stable than imidazole. In the gas phase, benzimidazole is more basic than imidazole, but only by $1.7 \mathrm{kcal} \mathrm{mol}^{-1}$. The basicity increase is small because of the stable neutral form of benzimidazole. An analogous isodesmic reaction can also be calculated for the pair pyrazole - indazole (see Table 2). Fusing an aromatic ring to pyrazole also increases its GB value moderately, by $2.3 \mathrm{kcal} \mathrm{mol}^{-1}$. The slightly bigger basicity increase compared to imidazole-benzimidazole pair comes from the less stable neutral in the case of indazole.

However, in both studied solvents imidazole is by around 1.3-1.5 $\mathrm{p} K_{\mathrm{a}}$ units more basic than benzimidazole. Besides the electron distribution, an additional reason for a decrease in the basicity of benzimidazole is solvation: the difference in the solvation energy between cation and neutral is $-53 \ldots-54 \mathrm{kcal} \mathrm{mol}^{-1}$ in the case of imidazole and $-49 \mathrm{kcal} \mathrm{mol}^{-1}$ in the case of benzimidazole in water. In $\mathrm{MeCN}$ the same differences are $-53 \ldots-55 \mathrm{kcal} \mathrm{mol}^{-1}$ and $-48 \ldots-51$ kcal $\mathrm{mol}^{-1}$, respectively. The differences between these energies between imidazole and benzimidazole are smaller than the threshold that we have defined above. Nevertheless it is encouraging to see that differences in solvation energies agree very well with the differences in the $\mathrm{p} K_{\mathrm{a}}$ values. A similar trend is observed with pyrazole and indazole where the former one is by 1.2-1.5 $\mathrm{p} K_{\mathrm{a}}$ units more basic in both studied solvents. The differences in the solvation energy between the protonated and neutral form of pyrazole and indazole in water are $-58 \ldots-60 \mathrm{kcal} \mathrm{mol}^{-1}$ and $-53 . .-55 \mathrm{kcal} \mathrm{mol}^{-1}$, respectively, while in MeCN these are $-58 \ldots-$ $59 \mathrm{kcal} \mathrm{mol}^{-1}$ and $-52 \ldots-54 \mathrm{kcal} \mathrm{mol}^{-1}$. This is again an effect of dispersing the positive charge over the larger system in benzo-annulated derivatives, which lowers the effective stabilization by solvation. In imidazole and pyrazole the excess positive charge is condensed in a smaller framework, leading to much stronger solvation in polar solvents such as $\mathrm{MeCN}$ and $\mathrm{H}_{2} \mathrm{O}$. 1,2,3-benzotriazole is by $7.8 \mathrm{kcal} \mathrm{mol}^{-1}$ more basic in the gas phase than 1,2,3-triazole, which is a much higher difference than previously observed with 5-member diazines and corresponding benzodiazines, being rather similar to 6-member rings. The dominant effect here is probably the increase of the charge density in the highly-electronegative 5-member 
ring at the expense of the 6-member ring, reversing the situation observed in the imidazolebenzimidazole pair. An isodesmic reaction analogous to reaction 15 (Table 2) shows that the basicity increase comes mainly from the less stable neutral form of benzotriazole. The more stable protonated benzotriazole is also an important factor. The basicity order remains the same in both solvents: 1,2,3-benzotriazole is by $1.0 \mathrm{p} K_{\mathrm{a}}$ units more basic than 1,2,3-triazole in $\mathrm{MeCN}$ and by and 1.47 units in water.

\section{Relative positions of nitrogen atoms in the ring}

The analysis of the basicity data shows that the presence of the $-\mathrm{N}=\mathrm{N}$ - bond in the ring destabilizes the neutral form due to the close vicinity of two nitrogen lone pair electrons and increases basicity. A nitrogen atom in either para or meta position to the protonation centre acts as an electron-withdrawing group and reduces basicity, the para position being more efficient, because the resonance effect with the protonation centre is not possible with the meta position. The relative basicity of the various heterocycles depends on the interplay of these factors.

The order of basicity of the three studied diazines is the same in all 3 media: pyridazine $>$ pyrimidine $>$ pyrazine. Isodesmic reactions (Table 2) reveal that, in the gas phase, pyridazine with its weak $-\mathrm{N}=\mathrm{N}$ - bond is significantly destabilized compared to pyrimidine both in neutral (22 $\left.\mathrm{kcal} \mathrm{mol}^{-1}\right)$ and protonated $\left(16 \mathrm{kcal} \mathrm{mol}^{-1}\right)$ forms. The difference between the relative stabilities, amounting to around $6 \mathrm{kcal} \mathrm{mol}^{-1}$, is probably caused by the extra destabilization of the neutral pyridazine by the repulsion between the neighbouring nitrogen lone pairs. Thus, the lower GB of pyrimidine compared to pyridazine is first of all caused by its more stable neutral form.

Pyrazine is the least basic of these three diazines. According to the isodesmic reactions, there is no additional stabilization of the neutral form like in pyrimidine, but the second nitrogen atom in the para position effectively acts as an electron-withdrawing group with respect to the protonation centre (similarly as, for example, a nitro group would), hence lowering the basicity.

The basicity order of the benzodiazines - phthalazine/cinnoline, quinazoline and quinoxaline - is the same as for the corresponding diazines in all three media, suggesting that the same basicity-influencing factors are in effect. Of the two benzo-derivatives of pyridazine phthalazine and cinnoline - the former is by $2.1 \mathrm{kcal} \mathrm{mol}^{-1}$ more basic in the gas phase, by $\mathrm{ca}$ $1 \mathrm{p} K_{\mathrm{a}}$ unit in $\mathrm{MeCN}$ and $1.18 \mathrm{p} K_{\mathrm{a}}$ units in water. Although there is a stabilizing peri effect to the nitrogen lone pair in both neutral and protonated cinnoline, still both forms of phthalazine 
are more stable according to the isodesmic reactions. These isodesmic reactions (eq 17 and eq 18) reveal that in the case of phthalazine the neutral is by $2.4 \mathrm{kcal} \mathrm{mol}^{-1}$ and the protonated form is by $4.6 \mathrm{kcal} \mathrm{mol}^{-1}$ more stable than in the case of cinnoline. The higher GB thus comes primarily from the more stable protonated phthalazine.

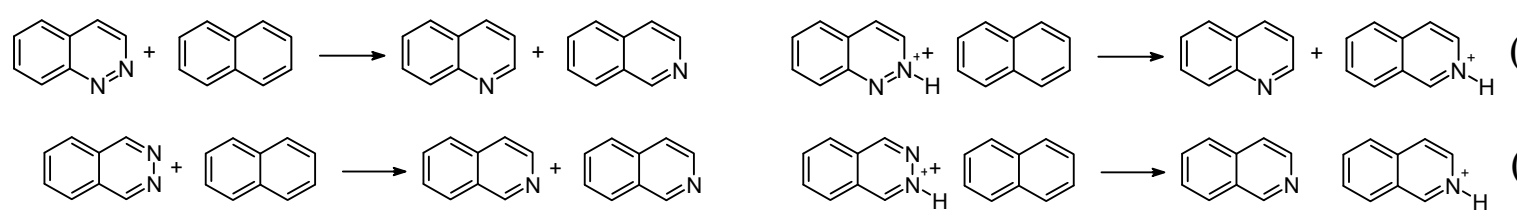

Isodesmic reactions 19 and 20 confirm that both imidazole and benzimidazole have higher gas-phase basicities than pyrazole and indazole (by $12.1 \mathrm{kcal} \mathrm{mol}^{-1}$ and $11.5 \mathrm{kcal} \mathrm{mol}^{-1}$, respectively) because of the more stable protonated forms caused by the efficient cationic resonance delocalization between the two nitrogen atoms. The overall basicity difference is somewhat decreased by the increased relative stability of the neutral forms as well, only to a lower extent.

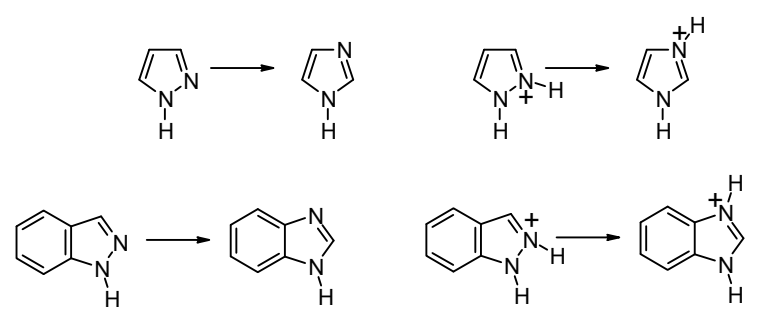

\section{Effect of electron-withdrawing substituents}

Introduction of electron-withdrawing groups has a general decreasing effect on the basicity of heterocycles, caused by both resonance and field-inductive effects of substituents. However, the extent of basicity decrease depends on the position of the substituent relative to the protonation centre and locations of partial charges in the molecule. It determines how strongly the substituent can deplete the electron density from the protonation centre in the neutral base and reduce the stabilization of the excess positive charge in the conjugate acid. It is of interest to compare the effect of nitro group on the basicity of the most basic 6-membered cycle (pyridine) and 5-membered cycle (imidazole). The addition of a nitro-group to positions 2 or 4 in imidazole lowers its GB value by $17.7 \mathrm{kcal} \mathrm{mol}^{-1}$ and $16.5 \mathrm{kcal} \mathrm{mol}^{-1}, \mathrm{p} K_{\mathrm{a}}(\mathrm{MeCN})$ by 9.51 and 8.70 units, and $\mathrm{p} K_{\mathrm{a}}\left(\mathrm{H}_{2} \mathrm{O}\right)$ by 7.76 and 7.11 units, respectively, which is very 
significant. Although in the imidazole cation the excess charge is delocalized across the ring, there is still a significant positive charge on the $\mathrm{H}$ atoms of the two - $\mathrm{NH}$ - groups. The nitro group, when inserted in position 2, is nearer to the positively charged centres than when it is in position 4 , so it has a stronger decreasing effect on the basicity in the former case.

In case of pyridine the nitro group lowers the GB value very similarly in all positions: by 14.3, 13.7 and $13.2 \mathrm{kcal} \mathrm{mol}^{-1}$ in positions 2, 3 and 4, respectively. The effect is notably smaller than in case of imidazole. In $\mathrm{MeCN}$, the nitro group in position 3 or 4 lowers the basicity by 5.4 and $4.7 \mathrm{p} K_{\mathrm{a}}$ units, respectively, while in position 2 the effect is $-8.8 \mathrm{p} K_{\mathrm{a}}$ units, being similar to that in imidazole. In $\mathrm{H}_{2} \mathrm{O}$ the nitro group in positions 2,3 and 4 decreases the basicity of pyridine by 7.7, 4.4 and $3.8 \mathrm{p} K_{\mathrm{a}}$ units, respectively. It must be noted that the quantitative basicity differences are somewhat less reliable in case of pyridines compared to imidazoles, since the literature $\mathrm{p} K_{\mathrm{a}}$ values of pyridines were inconsistent or unavailable and had to be estimated (see details in SI). However, the obtained data is sufficiently reliable to demonstrate the basicity trends.

Generally stronger effect of nitro group on 5-member rings is most probably due to the smaller ring size and its overall higher electron density.

The basicities of 5- and 6-nitro-substituted indazole are very similar in the gas phase and both solvents. It can be assumed that substituents in position 5 and 6 in indazole are located distantly enough from the protonation centre to have almost the same effect on the basicity in all studied media.

Benzimidazole-derived pesticides thiabendazole and carbendazim, as compared to unsubstituted benzimidazole, are more basic in the gas phase (by $3.9 \mathrm{kcal} \mathrm{mol}^{-1}$ and $2.1 \mathrm{kcal}$ $\mathrm{mol}^{-1}$, respectively), but less basic in both $\mathrm{MeCN}$ (by 1.10 and 1.28 units) and water (0.92 and 1.03 units) because of the thiazolyl and carbomethoxyamino functional groups. The factors making thiabendazole and carbendazim more basic in the gas phase are larger volume for charge delocalization and IMHB. These factors are weakened (IMHB) or compensated for by solvent molecules in solution (larger volume).

\section{Tautomerism of 1,2,3-triazole and 1,2,3-benzotriazole}

1,2,3-triazole and 1,2,3-benzotriazole have two different prototropic tautomers (eq 21). Our G4MP2 calculations show that in the gas phase 2- $H-1,2,3$-triazole and $1-H-1,2,3-$ benzotriazole, respectively, are the dominant forms. The $2-H-1,2,3$-triazole tautomer is by 3.6 kcal $\mathrm{mol}^{-1}$ more stable than the 1-H-1,2,3-triazole tautomer. For the protonated molecules hydrogens in positions 1 and 3 are always preferred for both molecules. This is in agreement 
with the previously reported large predominance of the 2- $\mathrm{H}-1,2,3$-triazole tautomer in the gas phase ${ }^{[37-39]}$ However, in the aqueous phase both $1-H$ and $2-H$ tautomers are present while the $2-H$ tautomer is still the favored by a factor of 2 to $4 .^{[38-40]}$ The increase of the $1-H$ tautomer content in aqueous solution comes from the relief of the lone pair repulsion by hydrogen bonding (destabilizing the 1- $H$ tautomer in the gas phase) and the higher stabilization of the 1$H$ tautomer by solvation because of its higher dipole moment. ${ }^{[38,40]}$

In the gas phase different theoretical methods give contradictory results in terms of the prevalence of the $1-H$ and $2-H$ tautomers, leading to the conclusion that they exist in comparable amounts. ${ }^{[41]}$ Experimental evidence shows that the content of the $1-\mathrm{H}$ tautomer in gas phase increases with temperature, implying that the $2-H$ tautomer is more stable. ${ }^{[42]}$ At the same time, our G4MP2 calculation show that 1-H-1,2,3-benzotriazole is more stable than the corresponding $2-H$ tautomer, yet only by $0.5 \mathrm{kcal} \mathrm{mol}^{-1}$. In the solution phase $1-H$ tautomer of 1,2,3-benzotriazole significantly predominates. ${ }^{[43,44]}$

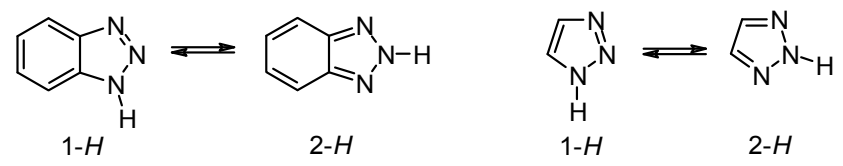

\section{Correlation of basicities in different media}

Figure 3 presents the correlation of $\mathrm{p} K_{\mathrm{a}}$ values in $\mathrm{MeCN}$ experimentally determined in this work against aqueous $\mathrm{p} K_{\mathrm{a}}$ values found from literature (where available). The overall correlation is described by the equation:

$$
\begin{gathered}
\mathrm{p} K_{\mathrm{a}}(\mathrm{MeCN})=1.20 \mathrm{p} K_{\mathrm{a}}\left(\mathrm{H}_{2} \mathrm{O}\right)+6.57 \\
s(\text { intercept })=0.15 ; s(\text { slope })=0.04 ; n=28 ; r^{2}=0.97 ; S=0.50 .
\end{gathered}
$$




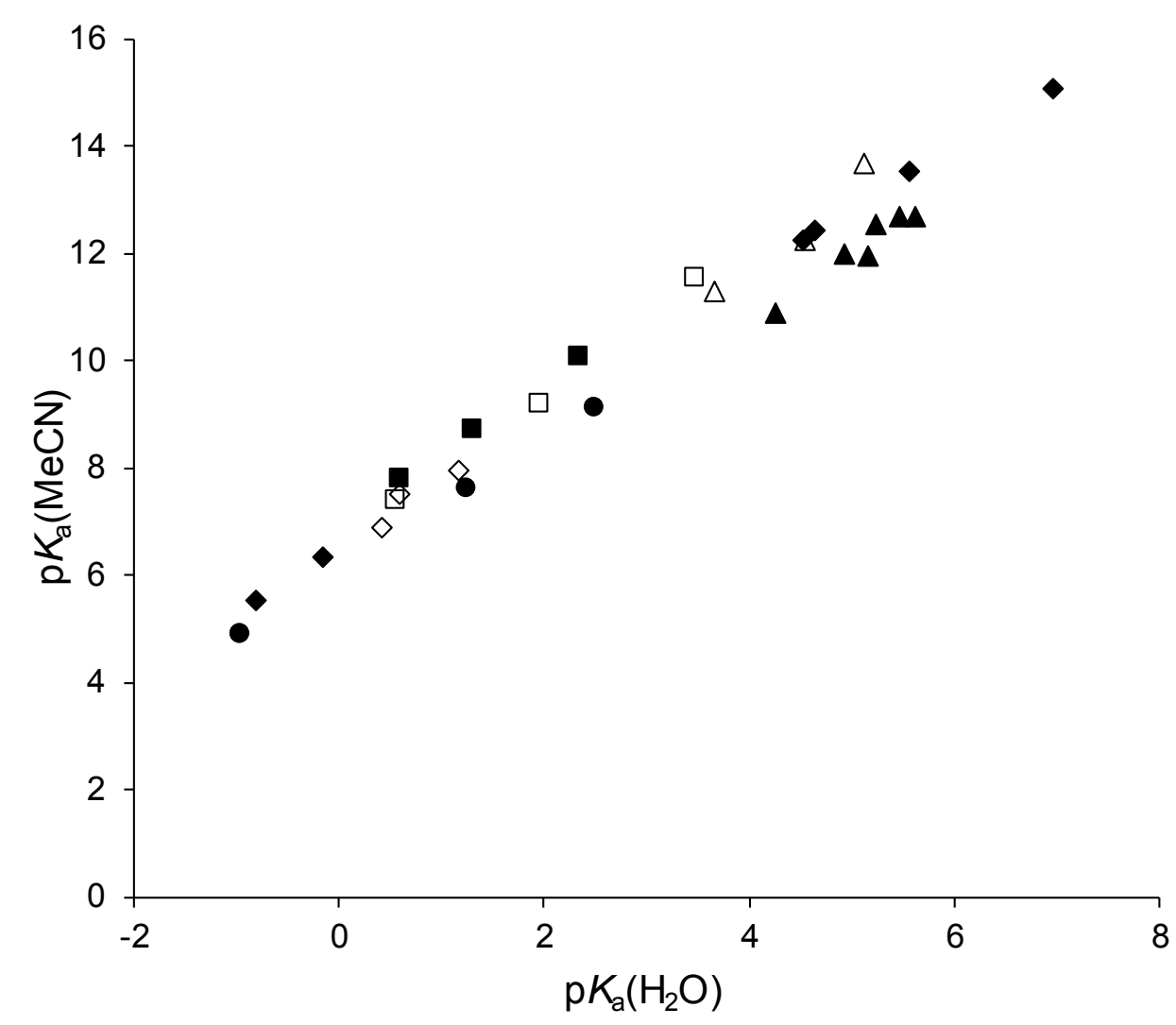

Figure 3. Correlation of the basicities of the studied bases in water and acetonitrile (filled triangles - pyridines, filled circles - indazoles, squares - diazines, filled diamonds - imidazoles, empty squares - benzodiazines, empty triangles - chelating compounds, empty diamonds - other compound types). The $\mathrm{p} K_{\mathrm{a}}$ values of uracil, thymine (different protonation sites) and quino[7,8- $h$ ]quinoline (no experimental $\mathrm{p} K_{\mathrm{a}}$ in water) were not included.

From Figure 3 it can be seen that there is quite a good correlation between basicities in $\mathrm{MeCN}$ and water, which includes all the different classes of heterocyclic compounds. An even better correlation can be obtained for only the different imidazoles (eq 23). The previously published $\mathrm{p} K_{\mathrm{a}}$ values of $5-\mathrm{NO}_{2}$-benzimidazole and $2-\mathrm{NH}_{2}$-benzimidazole are also included in this correlation. ${ }^{[17]}$

$$
\begin{gathered}
\mathrm{pKa}(\mathrm{MeCN})=1.26 \mathrm{p} K_{\mathrm{a}}\left(\mathrm{H}_{2} \mathrm{O}\right)+6.47 \\
s(\text { intercept })=0.13 ; s(\text { slope })=0.03 ; n=8 ; r^{2}=0.997 ; S=0.22 .
\end{gathered}
$$

The correlation between $\mathrm{p} K_{\mathrm{a}}$ values in $\mathrm{MeCN}$ and $\mathrm{GB}$ values is much poorer. This makes sense because $\mathrm{MeCN}$ and the gas phase are more notably different media than $\mathrm{MeCN}$ and water are. The equation for this correlation is:

$$
\mathrm{p} K_{\mathrm{a}}(\mathrm{MeCN})=0.29 \mathrm{~GB}-51.9
$$




$$
s(\text { intercept })=5.0 ; s(\text { slope })=0.02 ; n=31 ; r^{2}=0.84 ; S=1.5 \text {. }
$$

\section{Conclusions}

We presented 58 previously unpublished basicity values including 30 experimental $\mathrm{p} K_{\mathrm{a}}$ values in $\mathrm{MeCN}, 22$ calculated GB values, 4 calculated $\mathrm{p} K_{\mathrm{a}}$ values in $\mathrm{MeCN}$ and 2 calculated $\mathrm{p} K_{\mathrm{a}}$ values in $\mathrm{H}_{2} \mathrm{O}$ for a set of various conjugated nitrogen heterocycles. Analysis of the compiled data reveals that the main factors determining the basicity in the gas phase include: the ability of the molecule to delocalize the resulting positive charge across as large a $\pi$-system as possible once protonated, and different steric and stereoelectronic effects (e.g. presence of a peri hydrogen) operating in the neutral and/or protonated forms of the compound. The same factors operate in solution, yet their effect may be eclipsed by solvation phenomena like steric hindrance to solvation. Therefore, in solution, the fusion of an additional benzene ring does not always lead to a basicity increase as it leaves less hotspots with excess charge for an efficient solvation. This effect can be either basicity-increasing or decreasing, depending on the ring size, number and position of nitrogen atoms and medium.

Introduction of a second nitrogen atom into pyridine leads to a basicity decrease as it acts similarly to an electron withdrawing group. The extent of the basicity decrease is lowest in the presence of a $-\mathrm{N}=\mathrm{N}$ - bond, which increases basicity by the repulsion between nitrogen lone pairs, which destabilizes the neutral molecule. The basicity decreasing effect of a stronger electron withdrawing groups, such as the nitro group, depends on its distance from the protonation centre. This effect of the nitro group on the basicity is especially strong in 5membered rings because of their intrinsically higher electron density.

We showed that a good correlation between the $\mathrm{p} K_{\mathrm{a}}$ values in $\mathrm{MeCN}$ and $\mathrm{H}_{2} \mathrm{O}$ exists for various non-chelating heterocycles with the protonation centre on a $\mathrm{N}$ atom, which can be further improved by correlating only basicities of similar groups of compounds (e.g. imidazoles).

\section{Experimental Section}

\section{Chemicals}

Trifluoromethanesulfonic acid (TfOH, Aldrich 99+\%) and tertbutyliminotris(pyrrolidino)phosphorane ( $t$-BuP1(pyrr), Aldrich $\geq 97 \%$ ) were used to prepare acidic and basic titrant solutions. Commercial MeCN (Romil $190 \mathrm{SpS}$ far UV/gradient 
quality) was used as the solvent after drying on molecular sieves ( $3 \AA$ ), which was found to lower its water content mostly to the range of 2-4 ppm (never above $6 \mathrm{ppm}$ ). The water content was determined by Karl Fischer titration using a Mettler Toledo DL32 coulometer with the Hydranal ${ }^{\circledR}-$ Coulomat $\mathrm{AD}$ reagent (Riedel-de Haën). This method has been previously used to determine low water contents in aprotic solvents. ${ }^{[45]}$ Ionic liquid 1-hexyl-3methylimidazolium bis(trifluoromethylsulfonyl)imide $\left(\mathrm{C}_{6} \operatorname{mimNTf} 2\right.$, Aldrich $\left.98 \%\right)$ was used as salt bridge electrolyte. The origin of the measured bases was the following: quino[7,8$h$ ]quinoline was synthesized according to a modification of the procedure of Zirnstein et $a{ }^{[46,47]}$. Phenanthroline (Chemapol, "pure for analysis"), 2,2'-biquinoline (Trest Soyuzreaktiv, "pure"), 7,8-benzoquinoline (Merck, for GC), quinoline (Aldrich, 98\%), pyridine (Fluka, $>99.8 \%$ ), isoquinoline (Fluka, analytical standard), acridine (Fluka, >97\%), 2,2'-bipyridine (a kind gift from Prof. M. Mishima, Kyushu University), quinazoline (Aldrich, 99\%), pyrimidine (Aldrich, >98\%), phthalazine (Aldrich, 98\%), pyridazine (Alfa Aesar, 98+\%), quinoxaline (Fluka, analytical standard), pyrazine (Fluka, analytical standard), benzimidazole (Aldrich, 98\%), thiabendazole (Dr. Ehrenstorfer $\mathrm{GmbH}$, analytical standard), carbendazim (Dr. Ehrenstorfer $\mathrm{GmbH}$, analytical standard), 2- $\mathrm{NO}_{2}$-imidazole (Fluka, >98\%), 4- $\mathrm{NO}_{2}$-imidazole (Aldrich, 97\%), imidazole (Sigma, $\geq 99 \%$ ), pyrazole (Aldrich, 98\%), indazole (Aldrich, 98\%), 6- $\mathrm{NO}_{2}$-indazole (Aldrich, 97\%), 5- $\mathrm{NO}_{2}$-indazole (Aldrich, $\geq 99 \%$ ), benzotriazole (Reakhim, "pure for analysis"), 1,2,3-triazole (Aldrich, 97\%), caffeine (a kind gift from Prof. Tullio Ilomets), uracil (Fluka, $\geq 99 \%$ ), thymine (Sigma, $\geq 99 \%$ ). The structures of all these heterocyclic compounds are presented on Figure 1.

\section{Measurements of $\mathrm{p} K_{\mathrm{a}}$ values}

Spectrophotometry. The experimental setup, methodology and data treatment method of the spectrophotometric $\mathrm{p} K_{\mathrm{a}}$ determination were essentially the same as described in previous works. ${ }^{[17,26,27]}$ A brief description is given here. The determination of $\mathrm{p} K_{\mathrm{a}}$ values in $\mathrm{MeCN}$ is based on differences in basicities of two bases where the first substance is a heterocyclic compound of an unknown basicity and the other one is a reference base with a previously known $\mathrm{p} K_{\mathrm{a}}$ value. Both compounds individually and the mixture of these two compounds is spectrophotometrically titrated in order to obtain the spectra of the neutral and fully protonated forms. It is preferred that the spectra of the neutral and protonated forms of the studied compound and reference compound are different and that the absorption maxima of both compounds are at different wavelengths. Using these spectral data it is possible to calculate the dissociation levels $\alpha=[\mathrm{B}] /\left([\mathrm{B}]+\left[\mathrm{BH}^{+}\right]\right)$of the conjugate acids of both bases in 
all mixtures formed during titration. From these $\alpha$ values, differences in $\mathrm{p} K_{\mathrm{a}}$ values $\left(\Delta \mathrm{p} K_{\mathrm{a}}\right.$, eq 25) are calculated.

$$
\Delta \mathrm{p} K_{\mathrm{a}}=\log \frac{\alpha_{1}\left(1-\alpha_{2}\right)}{\alpha_{2}\left(1-\alpha_{1}\right)}
$$

$\mathrm{TfOH}$ and $t$-BuP1(pyrr) were used as acidic and basic titrants for all the titrations. All spectrophotometric titrations were carried out using a Perkin Elmer Lambda 40 UV-Vis spectrophotometer which was connected to an external compartment inside a MBraun Unilab glovebox with optical fiber cables. The glovebox was filled with $99.999 \%$ pure argon; moisture and oxygen contents inside the glovebox were monitored and were always under 10 ppm during the experiments. Bases with previously published $\mathrm{p} K_{\mathrm{a}}$ values were used as reference bases. ${ }^{[17,27]}$ The same $\mathrm{p} K_{\mathrm{a}}$ determination method has already been used for acidity or basicity determinations in different solvents e.g. 1,2-dichloroethane ${ }^{[20]}$, tetrahydrofuran ${ }^{[19]}$, acetonitrile $^{[17]}$.

Differential potentiometry. $\Delta \mathrm{p} K_{\mathrm{a}}$ in $\mathrm{MeCN}$ was also measured using differential potentiometry with two metal-coated glass electrodes ${ }^{[48]}$ (obtained from the Laboratory of Glass Electrochemistry, St. Petersburg State University) similarly as described in ref [49] with a potentiostat instead of a $\mathrm{pH}$ meter. Also the experiment time was changed from $2.15 \mathrm{~min}$ to $1.30 \mathrm{~min}$. The $\Delta \mathrm{p} K_{\mathrm{a}}$ values were calculated from the measured absolute $\mathrm{pH}$ (see ref [50] for details about the absolute $\mathrm{pH}$ concept) differences of two partially neutralized base solutions in $\mathrm{MeCN}$ with a known ratio of protonated and deprotonated forms (eq 26). The ratio of the neutral and protonated forms was determined by UV-Vis spectrophotometry. Salt bridge electrolyte was $\mathrm{C}_{6}$ mimNTf $_{2}$ and liquid junction potentials cancel out in these experiments. The differential potentiometry measurements of relative basicity were made outside of the glove box because of technical reasons and the water content in the solutions was $140-200$ ppm. However, we have earlier found that water content in the range of $200 \mathrm{ppm}$ does not have marked influence on $\Delta \mathrm{p} K_{\mathrm{a}}$ values of bases. ${ }^{[51]}$

$$
\Delta \mathrm{p} K_{\mathrm{a}}=\Delta \mathrm{pH}-\log \frac{\left[\mathrm{B}_{1}\right]}{\left[\mathrm{B}_{1} \mathrm{H}^{+}\right]}+\log \frac{\left[\mathrm{B}_{2}\right]}{\left[\mathrm{B}_{2} \mathrm{H}^{+}\right]}
$$

\section{Quantum chemical calculations}

Gas phase energies. The gas-phase basicity $\left(\mathrm{GB}=-\Delta G_{\mathrm{b}}\right)$ of a compound (B) is defined by the following equation:

$$
\mathrm{B}+\mathrm{H}^{+} \stackrel{\Delta G_{\mathrm{b}}}{\rightleftarrows} \quad \mathrm{BH}^{+}
$$


All Gibbs free energy values employed in the calculation of the GB values and energies of isodesmic reactions were obtained using the G4MP2 methodology ${ }^{[52]}$ implemented in the Gaussian 09 software package ${ }^{[53]}$. The G4MP2 method uses B3LYP/6-31G(2df,p) optimized geometries to calculate vibrational frequencies and thermal corrections. Wherever applicable, different starting geometries of neutral and protonated bases were used in order to ensure that the most stable conformer of each investigated particle has been found. In case of many possible protonation sites within the molecule the most stable protonated forms were identified. The minimum-energy conformers of $\mathrm{B}$ and $\mathrm{BH}^{+}$were used for $\mathrm{GB}$ calculations. All stationary points were found to be true minima, as evidenced by the absence of imaginary frequencies in the corresponding vibrational spectra $(\mathrm{NImag}=0)$.

Results from the quantum chemical calculations were also used for the calculations of free energy changes in isodesmic reactions. Isodesmic reactions are chemical reactions (hypothetical or actual) in which both the number and the type of chemical bonds in the reactants and products are the same on both sides of a reaction. This concept can be used to elucidate the effect of molecular structure on basicity. ${ }^{[54,55]}$ In that case the same isodesmic reactions are calculated for both neutral molecules and their protonated forms, which allows to estimate the energetic contributions of structural effects. ${ }^{[56]}$ Usually it is preferred to use enthalpies for the calculations of isodesmic reactions but when both sides of the reaction equation have the same number of molecules and no intramolecular cyclization occurs then Gibbs free energies can also be utilized. ${ }^{[56]}$ In this work free energies are used for all isodesmic reaction calculations in order to make the obtained values directly comparable with differences in GB values.

Solvation energies of neutral and protonated species were computed using $\mathrm{SMD}^{[57]}$ and COSMO-RS ${ }^{[58-60]}$ methods.

In case of the SMD implicit solvation model (implemented in Gaussian 09 ${ }^{[53]}$ software) the geometry optimization and vibrational frequency calculations were carried out in 3 media (water, acetonitrile, gas phase) using M06-2X functional and 6-31G(d) basis set. The vibrational spectra were checked for imaginary frequencies, the absence of which was taken as a proof of the stationary point being a true minimum. The solvation energy of a species was calculated by subtracting its gas-phase energy from its total energy in the solvent. All conformers (including tautomers) of the neutral and protonated bases were calculated, and the lowest energies obtained in every medium were used for the calculation of solvation energy, disregarding of the possible mismatch of the geometries of the lowest-energy species. 
In the case of COSMO-RS method the first step (carried out using TURBOMOLE V6.5 ${ }^{[61]}$ software package) is a quantum chemical calculation yielding the equilibrium geometry and partial charge distribution on the surface of the molecule (so-called sigma-profile). Geometry optimization was performed using DFT method at BP/TZVP level of theory. All stable conformers (including tautomers) of the molecules were found and vibrational analysis was carried out to ensure that the obtained geometries correspond to true energy minima. SCF convergence threshold of $10^{-7}$ Hartree, gridsize $\mathrm{m} 3 / \mathrm{m} 4$ and geometry convergence threshold of $10^{-6} \ldots 10^{-8}$ Hartree were used. In cases where imaginary frequencies were found in the vibrational spectra, the geometries were reoptimized using finer grid (m5), larger basis set (def2-TZVPD), stricter geometry convergence criteria, or the combination of the above. Subsequently a single-point energy calculation with def2-TZVPD basis set and, in case of ideal conductor, Fine Cavity parameter was performed. The second step is statistical thermodynamics procedure (carried out using COSMOtherm $X$ software, Version C3.0 Release $17.01^{[60,62]}$, with parametrization BP_TZVPD_FINE_C30_1701) that accounts for the solute-solvent interactions and yields the energies of the species in the solution, from which the desired solute properties are calculated. Gas-phase SCF energies obtained at TZVP//TZVPD level of theory were employed for the calculation of the gas-phase chemical potential instead of the estimates computed by COSMOtherm $X$ by default. All conformers of the species were taken into account using the inherent conformer-weighing procedure in COSMOtherm $X$.

The computations in liquids are considerably more complicated and, as a rule, less precise than the matching computations in vacuo, which may put in some doubt the accuracy of absolute values of calculated solvation energies not supported by any experimental counterparts. At the same time, comparing solvation energies of different but structurally related neutrals (or cations) computed by the same approach within the same solvent is meaningful, especially if the solvation energy difference is sufficiently large. In this work we consider that solvation energy differences can be used for supporting discussions if the corresponding difference is at least $5 \mathrm{kcal} \mathrm{mol}^{-1}$. This threshold comes from our earlier experience with various correlations of combinations of GB and solvation energy differences with $\mathrm{p} K_{\mathrm{a}}$ values in the same solvent.

Computational $p K_{a}$ values in solution. In the absence of experimental data the corresponding $\mathrm{p} K_{\mathrm{a}}$ values were obtained from correlations involving COSMO-RS results and experimental data of a set of compounds (similar to the compound of interest) with known $\mathrm{p} K_{\mathrm{a}}$ values. Please see the Supporting Information for detailed descriptions of each case. The uncertainties 
of the computational $\mathrm{p} K_{\mathrm{a}}$ values were generally estimated as two times the standard deviation of the regression and we assess their coverage probability as $90 \%$. In the case of aqueous $\mathrm{p} K_{\mathrm{a}}$ of quino[7,8- $h]$ quinoline the uncertainty estimate is based on pooling the expected reliabilities of the different alternative approaches used to evaluate the $\mathrm{p} K_{\mathrm{a}}$ value and is also expected to have coverage probability of $90 \%$.

\section{Acknowledgements}

This research was supported by the EU through the European Regional Development Fund (TK141 “Advanced materials and high-technology devices for energy recuperation systems") and by Ministry of Education and Science of Estonia (the institutional research grant No. IUT20-14). R.V. gratefully acknowledge the Croatian Science Foundation for a financial support through project IP-2014-09-3386. We would also like to thank Nena Radic for useful discussions.

\section{Keywords}

Nitrogen heterocycles, basicity, solvent effects, intramolecular hydrogen bond, peri effect 


\section{References}

[1] J. A. Joule, K. Mills, Heterocyclic Chemistry, Wiley, Hoboken, N.J, 2009.

[2] P. Gilli, L. Pretto, V. Bertolasi, G. Gilli, Acc. Chem. Res. 2009, 42, 33-44.

[3] D. Hörter, J. B. Dressman, Adv. Drug Delivery Rev. 2001, 46, 75-87.

[4] G. G. Gallo, C. R. Pasqualucci, P. Radaelli, G. C. Lancini, J. Org. Chem. 1964, 29, 862865.

[5] V. Lopez, J. Catalan, R. M. Claramunt, C. Lopez, E. Cayon, J. Elguero, Can. J. Chem. 1990, 68, 958-959.

[6] A. Albert, J. N. Phillips, J. Chem. Soc. 1956, 1294-1304.

[7] K. Chamberlain, A. A. Evans, R. H. Bromilow, Pestic. Sci. 1996, 47, 265-271.

[8] A. Albert, R. Goldacre, J. Phillips, J. Chem. Soc. 1948, 2240-2249.

[9] J. Catalan, R. M. Claramunt, J. Elguero, J. Laynez, M. Menendez, F. Anvia, J. H. Quian, M. Taagepera, R. W. Taft, J. Am. Chem. Soc. 1988, 110, 4105-4111.

[10] A. Avdeef, Absorption and Drug Development: Solubility, Permeability, and Charge State, John Wiley \& Sons, Inc., Hoboken, NJ, USA, 2003.

[11] H. Wang, C. Burda, G. Persy, J. Wirz, J. Am. Chem. Soc. 2000, 122, 5849-5855.

[12] A. C. M. Paiva, L. Juliano, P. Boschcov, J. Am. Chem. Soc. 1976, 98, 7645-7648.

[13] V. Palm, Ed., Tables of Rate and Equilibrium Constants of Heterolytic Organic Reactions, VINITI, Moscow-Tartu, 1975.

[14] G. Bellér, M. Szabó, G. Lente, I. Fábián, J. Org. Chem. 2016, 81, 5345-5353.

[15] J. Catalan, J. Elguero, Adv. Heterocycl. Chem. 1987, 41, 187-274.

[16] J. W. Bunting, D. D. Perrin, J. Chem. Soc. B 1966, 436-438.

[17] I. Kaljurand, A. Kütt, L. Sooväli, T. Rodima, V. Mäemets, I. Leito, I. A. Koppel, J. Org. Chem. 2005, 70, 1019-1028.

[18] K. Izutsu, Acid-Base Dissociation Constants in Dipolar Aprotic Solvents, IUPAC Chemical Data Series No. 35, Blackwell Scientific Publication, Oxford, 1990.

[19] I. Kaljurand, T. Rodima, A. Pihl, V. Mäemets, I. Leito, I. A. Koppel, M. Mishima, J. Org. Chem. 2003, 68, 9988-9993.

[20] K. Kaupmees, R. Järviste, I. Leito, Chem. Eur. J. 2016, 22, 17445-17449.

[21] I. Kaljurand, I. A. Koppel, A. Kütt, E.-I. Rõõm, T. Rodima, I. Koppel, M. Mishima, I. Leito, J. Phys. Chem. A 2007, 111, 1245-1250.

[22] P. J. Linstrom, W. G. Mallard, Eds. , NIST Chemistry WebBook, NIST Standard Reference Database 69, National Institute Of Standards And Technology, Gaithersburg MD, 20899, Doi:10.18434/T4D303, Retrieved April 28, 2017.

[23] As is customary among organic chemists, the term "pKa of base $X$ " is used in this paper with the actual meaning of $\mathrm{pKa}$ of the conjugate acid of base $\mathrm{X}$.

[24] J.-L. M. Abboud, R. Notari, Pure Appl. Chem., PAC 1999, 71, 645-718.

[25] C. Reichardt, Solvents and Solvent Effects in Organic Chemistry, Wiley-VCH, Weinheim, 2003.

[26] I. Kaljurand, T. Rodima, I. Leito, I. A. Koppel, R. Schwesinger, J. Org. Chem. 2000, 65, 6202-6208.

[27] K. Haav, J. Saame, A. Kütt, I. Leito, Eur. J. Org. Chem. 2012, 2012, 2167-2172.

[28] R. M. C. Dawson, D. C. Elliott, W. H. Elliott, K. M. Jones, Data for Biochemical Research (3rd Edition), Oxford Science Publications, OUP, Oxford, 1986.

[29] W. L. F. Armarego, Fused Pyrimidines, Part 1 - Quinazolines, Interscience Publishers, New York, 1967.

[30] F. Hibbert, J. Chem. Soc., Perkin Trans. 2 1974, 1862-1866. 
[31] R. J. Schwamm, R. Vianello, A. Maršavelski, M. Á. García, R. M. Claramunt, I. Alkorta, J. Saame, I. Leito, C. M. Fitchett, A. J. Edwards, et al., J. Org. Chem. 2016, 81, 76127625.

[32] I. Leito, I. A. Koppel, I. Koppel, K. Kaupmees, S. Tshepelevitsh, J. Saame, Angew. Chem. Int. Ed. 2015, 54, 9262-9265.

[33] R. S. Hosmane, J. F. Liebman, Struct. Chem. 2009, 20, 693-697.

[34] H. Irving, D. H. Mellor, J. Chem. Soc. 1962, 5222-5237.

[35] K. J. Shaffer, M. Wenzel, P. G. Plieger, Polyhedron 2013, 52, 1399-1402.

[36] A. Bencini, V. Lippolis, Coord. Chem. Rev. 2010, 254, 2096-2180.

[37] F. Tomas, J. Catalan, P. Perez, J. Elguero, J. Org. Chem. 1994, 59, 2799-2802.

[38] J. R. Cox, S. Woodcock, I. H. Hillier, M. A. Vincent, J. Phys. Chem. 1990, 94, 54995501.

[39] J.-L. M. Abboud, C. Foces-Foces, R. Notario, R. E. Trifonov, A. P. Volovodenko, V. A. Ostrovskii, I. Alkorta, J. Elguero, Eur. J. Org. Chem. 2001, 2001, 3013-3024.

[40] A. Albert, P. J. Taylor, J. Chem. Soc., Perkin Trans. 2 1989, 1903-1905.

[41] L. T. Ueno, R. O. Ribeiro, M. S. Rocha, M. E. V. Suárez-Iha, K. Iha, F. B. C. Machado, J. Mol. Struct.: THEOCHEM 2003, 664-665, 207-215.

[42] J. Catalan, P. Perez, J. Elguero, J. Org. Chem. 1993, 58, 5276-5277.

[43] N. Jagerovic, M. Luisa Jimeno, I. Alkorta, J. Elguero, R. María Claramunt, Tetrahedron 2002, 58, 9089-9094.

[44] J. Poznański, A. Najda, M. Bretner, D. Shugar, J. Phys. Chem. A 2007, 111, 6501-6509.

[45] J. Saame, T. Rodima, S. Tshepelevitsh, A. Kütt, I. Kaljurand, T. Haljasorg, I. A. Koppel, I. Leito, J. Org. Chem. 2016, 81, 7349-7361.

[46] K. J. Shaffer, T. M. McLean, M. R. Waterland, M. Wenzel, P. G. Plieger, Inorg. Chim. Acta 2012, 380, 278-283.

[47] M. A. Zirnstein, H. A. Staab, Angew. Chem. Int. Ed. Engl. 1987, 26, 460-461.

[48] W. Vonau, U. Guth, J. Solid State Electrochem. 2006, 10, 746-752.

[49] A. Suu, L. Jalukse, J. Liigand, A. Kruve, D. Himmel, I. Krossing, M. Rosés, I. Leito, Anal. Chem. 2015, 87, 2623-2630.

[50] D. Himmel, S. K. Goll, I. Leito, I. Krossing, Angew. Chem. Int. Ed. 2010, 49, 68856888.

[51] K. Kaupmees, I. Kaljurand, I. Leito, J. Solution Chem. 2014, 43, 1270-1281.

[52] L. A. Curtiss, P. C. Redfern, K. Raghavachari, J. Chem. Phys. 2007, 127, 124105.

[53] M. Frisch, G. Trucks, H. Schlegel, G. Scuseria, M. Robb, J. Cheeseman, G. Scalmani, V. Barone, B. Mennucci, G. Petersson, et al., Gaussian 09, Revision B.01, Gaussian, Inc., Wallingford CT 2010.

[54] S. T. Howard, J. Am. Chem. Soc. 2000, 122, 8238-8244.

[55] E.-I. Rõõm, A. Kütt, I. Kaljurand, I. Koppel, I. Leito, I. A. Koppel, M. Mishima, K. Goto, Y. Miyahara, Chem. - Eur. J. 2007, 13, 7631-7643.

[56] A. Kütt, V. Movchun, T. Rodima, T. Dansauer, E. B. Rusanov, I. Leito, I. Kaljurand, J. Koppel, V. Pihl, I. Koppel, et al., J. Org. Chem. 2008, 73, 2607-2620.

[57] A. V. Marenich, C. J. Cramer, D. G. Truhlar, J. Phys. Chem. B 2009, 113, 6378-6396.

[58] A. Klamt, J. Phys. Chem. 1995, 99, 2224-2235.

[59] A. Klamt, V. Jonas, T. Bürger, J. C. W. Lohrenz, J. Phys. Chem. A 1998, 102, 5074 5085.

[60] F. Eckert, A. Klamt, AIChE J. 2002, 48, 369-385.

[61] TURBOMOLE V6.5 2013, a development of University of Karlsruhe and Forschungszentrum Karlsruhe GmbH, 1989-2007, TURBOMOLE GmbH, since 2007; available from http://www.turbomole.com. 
[62] F. Eckert and A. Klamt, COSMOtherm, Version C3.0, Release 17.01; COSMOlogic GmbH \& Co. KG. http://www.cosmologic.de. 
TOC Figure:

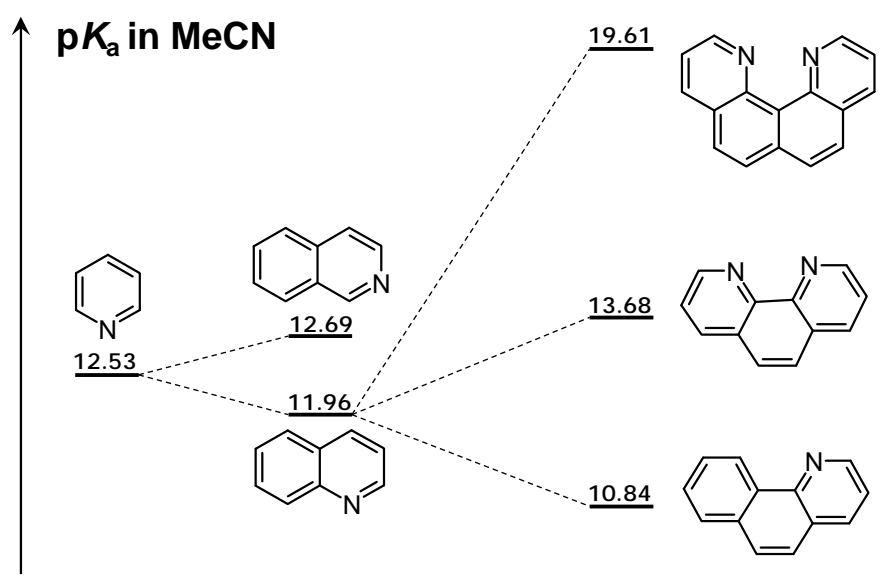

\section{TOC graphic text:}

Experimental $\mathrm{p} K_{\mathrm{a}}$ values in acetonitrile and gas-phase basicities of 30 conjugated heterocyclic compounds are presented. The basicity-determining structural and solvent effects are discussed and the basicity trends are rationalized by comparing the basicity data of structurally similar heterocycles in acetonitrile, water, the gas phase and by using isodesmic reactions.

\section{Key topic:}

Basicity of heterocycles 